\title{
Electroencephalography (EEG)-based detection, management, recovery and brain retraining tracking of Traumatic Brain Injury (TBI) when “Only Time Can Tell”
}

\author{
Miranda $\mathrm{P}^{1}$, Cox $\mathrm{CD}^{2}$, Alexander $\mathrm{M}^{1}$, Lakey JRT ${ }^{1 *}$ and Danev $\mathrm{S}^{3}$ \\ ${ }^{1}$ Department of Surgery and Biomedical Engineering, University of California Irvine, California, USA \\ ${ }^{2}$ Department of Neurology, David Geffen School of Medicine, University of California, Los Angeles, California, USA \\ ${ }^{3}$ Medeia Inc, Santa Barbara, CA, USA
}

\begin{abstract}
Traumatic brain injury (TBI) can be caused by accidents like road traffic accidents (RTA), sports injuries, and injuries at home. It is a major health issue, very often fatal and causing high morbidity, changing the lives of both the person injured and the families involved. Anticipating and preventing secondary injury and seizures post-trauma, defining severity of TBI, predicting TBI outcomes and arousal from coma or declaration of vegetative state or brain death form pivotal checkpoints in TBI management. Other challenges faced include identifying malingerers from genuine individuals with post-TBI morbidity, defining the severity of previous TBI in the field or previous injuries when reports are lost. Depending on both its severity and location it can cause a variety of post-TBI cognitive, sensory and tactile, and motor impairments. In such instances the present paper looks at how the electroencephalographs (EEG) like NeuralScan can and do contribute uniquely and significantly aiding in assessment, continuous/periodic evaluation during the course of recovery, brain-retraining and rehabilitation in evaluating temporal changes in neuronal functionality following TBI.
\end{abstract}

\section{Vital statistics on traumatic brain injury (TBI)}

To better appreciate the unique and valuable contributions that the high temporal resolution electroencephalograph (EEG) like NeuraScan provide in the detection, classification, treatment, management and rehabilitation of traumatic brain injury (TBI) a brief review of the key epidemiology, consequences, co-morbidities, neuropathophysiology and outcomes of TBI is appropriate. In 2016, the incidence of traumatic brain injury (TBI) was 27.08 million and prevalence was 55.50 million [1]. In 2018 the global incidence of TBI was 69 million individuals worldwide and predicted to be the third leading cause of mortality in 2020 [2-5]. Incidence rates based on TBI severity determined using 6 studies are that mild TBI affects approximately 55.9 million people each year (740 cases per 100,000 people), moderate TBI affects 7.64 million people each year (101 cases per 100,000 people), and severe TBI affects 5.48 million people each year ( 73 cases per 100,000 people) with the proportion of mild, moderate and severe being $81.02 \%, 11.04 \%$, and severe $7.95 \%$ respectively [5-10]. The causes of traumatic brain injury (TBI) range from falls, motor vehicle accidents (traffic and pedestrian), self-harm (falls, gunshot wounds-GSW), abuse/domestic (adult or children) violence, street violence, work/industrial/construction incidents (falls, blasts) and military maneuvers/terrorism, (falls, fire arms, blasts, explosions).

Following a TBI the duration from injury to recovery (Figure 1: LORETA images tracking injury to recovery taken using NeuralScan by Medeia) can vary depending on the duration between injury and commencement of treatment, severity and location of the injury. While earlier it was thought that only moderate-severe TBI survivors (50-65\%) experience debilitating emotional, psychological and neurocognitive consequences (Figures 2a and $2 \mathrm{~b}$ ) in recent year's studies have shown that individuals (athletes, military personnel and elderly) with mild TBI (mTBI) also share the same risk [4-7,11-16]. mTBI accounts for 1.63.8 million sports-related 320,000 military-related concussions [17-20]. The consequences of TBI affect personal, social and work life as well as influence the rate of age-related cognitive decline [20-29]. Military veterans with $\mathrm{mTBI}$ have been shown to be at a $56 \%$ increased risk of Parkinson disease (PD) [30]. Studies on TBI and the risk of dementia or Alzheimer's disease (AD) have shown no similar association [31].

Whether it's mild or, moderate or severe TBI though for some individuals return-to-normal it is uneventful for many others it requires a concerted and integrated approach on the part of a myriad medical specialties extending to family, social and occupational support where rehabilitation is concerned [32-38] an individual. Further compounding the issue is that many individuals with possible/probable mild TBI following sports injury, falls and road traffic accidents (RTA) etc do not seek treatment. A survey of 1381 individuals with TBI found $42 \%$ did not seek treatment with age, severity of TBI and injury occurring at home being factors associated with not seeking treatment $[32,39]$. Similarly, less than half of patients (41\% [343 patients]) reported having seen a medical practitioner about their mTBI at 2 weeks, and $44 \%$ (367 patients) reported seeing a medical practitioner by 3 months [40-42]. Another feature of mTBI is that very often individuals do not seek medical care, among those who do seek care there is a lack of followup care even if they tested positive on computed tomography (CT)

${ }^{\star}$ Correspondence to: Jonathan RT Lakey, PhD, MSM, Department of Surgery, 333 City Blvd West, Suite 1600, Orange, CA 92868, E-mail: jlakey@uci.edu

Received: May 28, 2020; Accepted: June 19, 2020; Published: June 21, 2020 


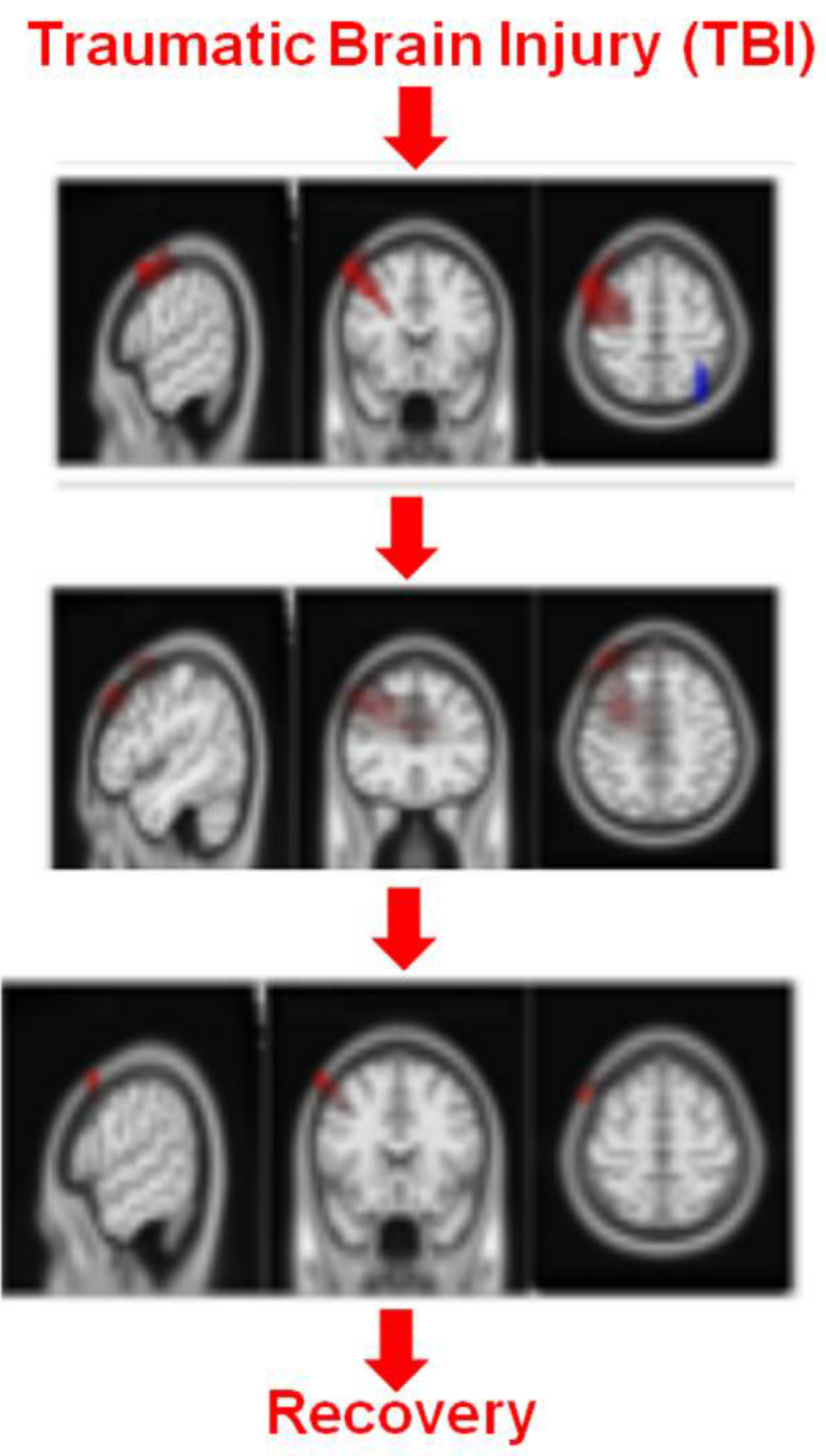

Figure 1. Working example of the dual use of eLORETA/sLORETA: To "track TBI" from injury to recovery, To "track Z-score retraining of the brain", LORETA Images taken using NeuralScan by Medeia

and post mTBi symptoms exist/persist symptoms this in turn results in longer-lasting symptoms which may have long-term consequences [40-42].

Another key aspect about TBI is it is dynamic. A brief overview of the neuropathology of TBI is presented in Figure 3 which illustrates how both the primary and secondary injuries influence outcomes [43-45]. Figure 3a presents the different types of primary injury that can occur, the consequences of which is the secondary injury (Figure 3b) which can happen within minutes or days following the trauma. The secondary injury is the result of the cascade of events (molecular, chemical, and inflammatory) that are activated following the primary injury [43-45]. Hence one of the main goals of TBI treatment protocols is to repair the primary injury and prevent secondary injury which if left unchecked can cause further cerebral damage [43-45].
Short and long term outcomes of traumatic brain injury (TBI) vary depending on the severity of injury (primary and secondary), comorbidities during hospitalization and following discharge, location of the injury, medical history prior to the TBI, previous TBI, presence of polytrauma [16,32-38,46-48]. At 8-years following a TBI, $19.8 \%$ and $46.5 \%$ were severely and moderately disabled respectively with $33.7 \%$ with good recovery among 86 individuals who participated in the study. Somatic complaints were balance $47.5 \%$, motricity $31 \%$, and headaches $36 \%$, cognitive complaints: memory $71 \%$, slowness $68 \%$, concentration $67 \%, 25 \%$ had anxiety and $23.7 \%$ for depression. $48.7 \%$ were employed in a productive job and $38 \%$ declared a salary loss since the TBI [46].

\section{When only time can tell}

Among the several studies aimed at determining blood, imaging and electrophysiology (EEG) based markers to classify, monitor and 

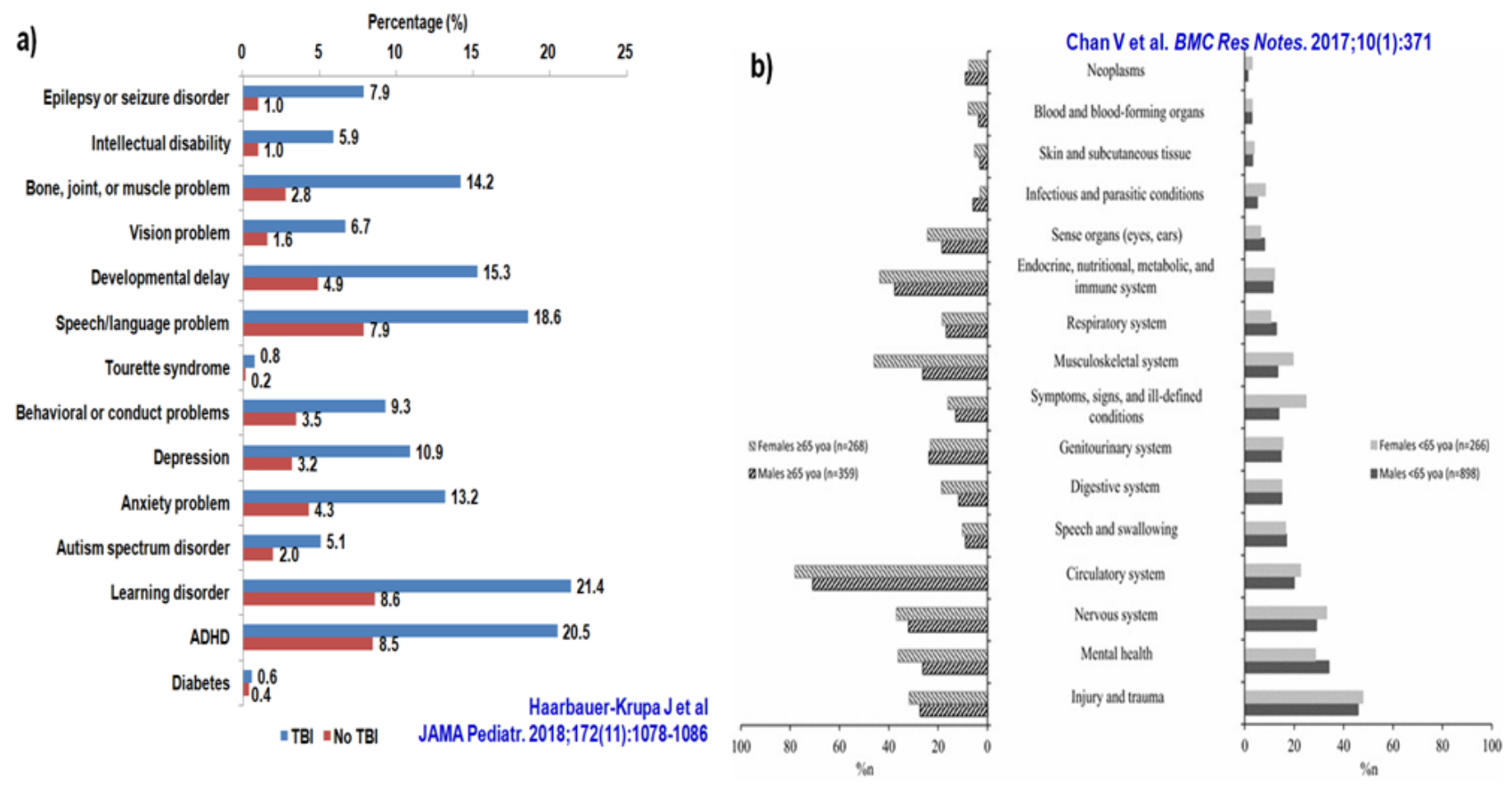

Figure 2. Prevalence of co-morbid conditions among a) Children (parent-reported), and b) $<65$ and $\geq 65$ year-old Adults following TBI

Jain, K. K. (2008) Drug Discovery Today

https://www.nap.edu/read/13121/chapter/6 Chapter 3

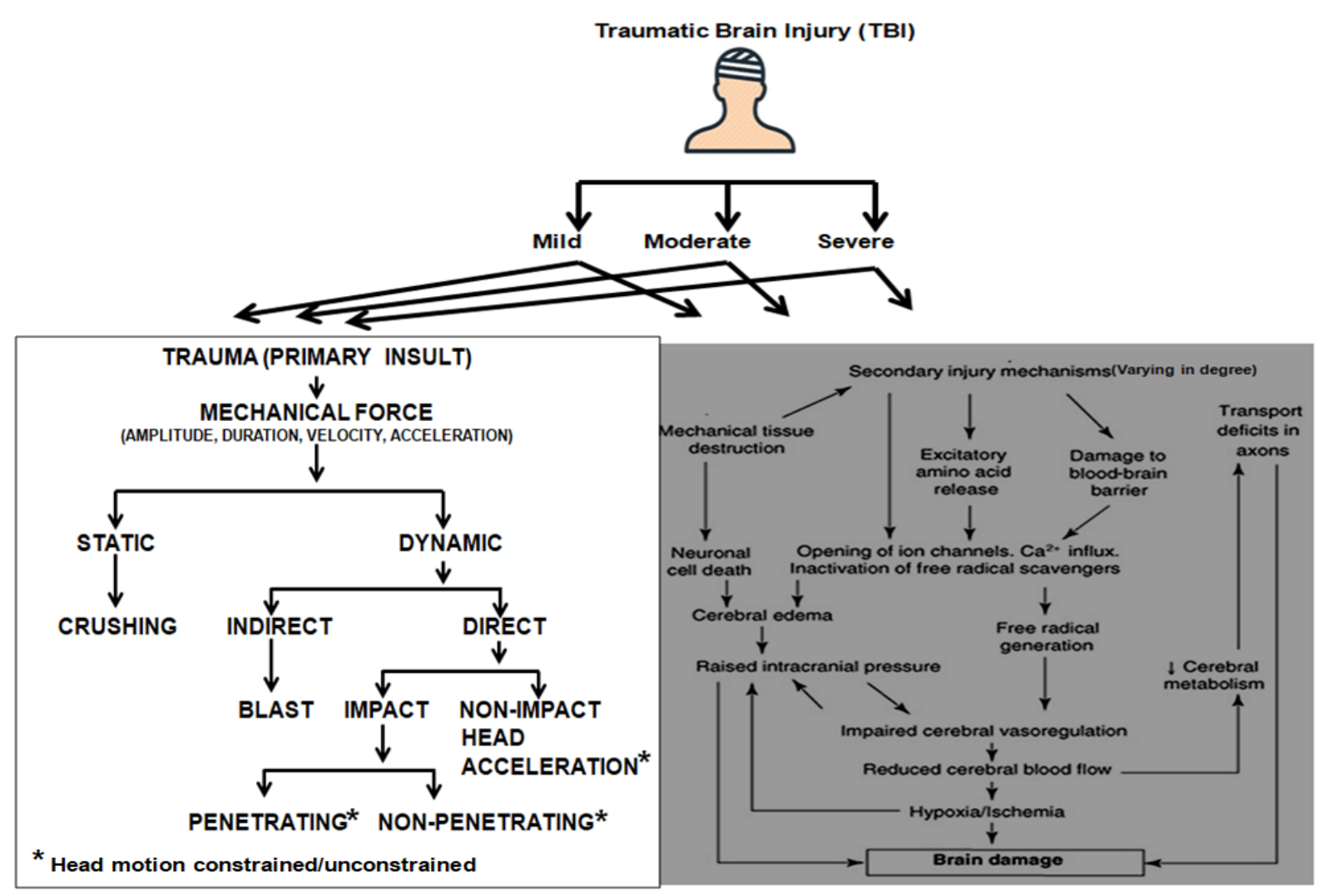

Figure 3. Trauma brain injury and its neuropathophysiology 
treat TBI the EEG (machines like NeuralScan by Medeia) remains one of the earliest neurodiagnostic assessment tools that was used $[49,50]$. Denis Williams recommended and demonstrated the use of the EEG both in evaluating progress in cerebral repair and when the damage is so slight that it cannot be detected by other imaging techniques [50]. He advocated the EEG as a useful tool when monitoring the brain following initial trauma, monitoring to prevent secondary injury and when planning treatment and rehabilitation (Figures $4 \mathrm{a}$ and $4 \mathrm{~b}$ ). Following a TBI there are several time points (as mentioned below) at which the high temporal resolution, quantitative EEG (QEEG) and LORETA for spatial resolution that EEG machines like NeuralScan by Medeia offer is key (Figures 1, 4a, 4b and 5).
Identification, Monitoring and treatment of Seizures following TBI: The portable non-invasive EEG allows for evaluating a patients electrophysiological status at the trauma site or bedside (emergency room/ trauma unit/operation theatre/intensive care unit-ICU) enabling identification of nonconvulsive seizures (NCS) following cerebral, trauma monitoring of treatment and categorization of the severity of the TBI [51-56]. NCS and periodic discharges (PD) following TBI contribute to disruption of brain metabolism [51-56]. Of the 94 patients with moderate-to-severe TBI seizures occurred in more than one in five patients during the 1st week following primary injury [51]. As NCS are found to occur frequently following a TBI and require continuous EEG (cEEG) monitoring for timely detection, prevention or treatment of NCS

\begin{tabular}{|c|c|c|c|c|c|}
\hline \multirow[b]{2}{*}{ EEG Parameters } & \multirow{2}{*}{$\begin{array}{c}\text { QEEG } \\
\text { Z-Scores }\end{array}$} & \multirow{2}{*}{$\begin{array}{c}\text { LORETA } \\
\text { 8 Functional } \\
\text { Networks }\end{array}$} & \multicolumn{3}{|c|}{ Brain Cortex-Brodmann Areas-Functional regions } \\
\hline & & & Brodmann Areas & \begin{tabular}{|c|} 
Total Brodmann \\
Pairs
\end{tabular} & $\begin{array}{c}\text { Brain Cortical } \\
\text { Regions }\end{array}$ \\
\hline \multirow{5}{*}{$\begin{array}{l}\text { - Brain waves } \\
\text { - Evoked } \\
\text { potentials } \\
\text { - ERPs } \\
\text { - Sleep Studies } \\
\text { - Resting EEG } \\
\text { (Eyes Open \& } \\
\text { Eyes Closed) }\end{array}$} & \multirow{8}{*}{$\begin{array}{l}\text { - 8-Functional } \\
\text { Network } \\
\text { - Amplitude } \\
\text { asymmetry } \\
\text { - Coherence } \\
\text { - Absolute phase } \\
\text { - Instantaneous } \\
\text { connectivity } \\
\text { - Lagged connectivity }\end{array}$} & Anxiety & $\begin{array}{l}\text { 4,6,7,10,13,21, } \\
\text { Amygdala }\end{array}$ & 42 & \multirow{8}{*}{$\begin{array}{l}\text { - Frontal lobe } \\
\text { - Parietal lobe } \\
\text { - Occipital lobe } \\
\text { - Temporal lobe } \\
\text { - Posterior } \\
\text { Cingulate, } \\
\text { - Anterior } \\
\text { Cingulate gyrus, } \\
\text { - Parahippocamp } \\
\text { al gyrus }\end{array}$} \\
\hline & & \begin{tabular}{|l|} 
Attention \\
Dorsal
\end{tabular} & $6,7,8,19,39,40$ & 30 & \\
\hline & & $\begin{array}{l}\text { Attention } \\
\text { Ventral }\end{array}$ & $10,11,19,21,37,44,45$ & 42 & \\
\hline & & $\begin{array}{l}\text { Default } \\
\text { Mode }\end{array}$ & $\begin{array}{l}7,10,11,19,22,29,30,31 \\
35,39,40\end{array}$ & 110 & \\
\hline & & Language & $\begin{array}{l}22,39,40,41,42,44,45 \\
\text { Left Hemisphere only }\end{array}$ & 21 & \\
\hline \multirow{3}{*}{$\begin{array}{l}\text { Amplitude, } \\
\text { Power, } \\
\text { Frequency, } \\
\text { - Latency }\end{array}$} & & Memory & $\begin{array}{l}\text { 7,9,24,30,31,32,33,40, } \\
\text { Hippocampus }\end{array}$ & 72 & \\
\hline & & Mood & $\begin{array}{l}10,11,13,23,24,32,33,4 \\
4,45,47\end{array}$ & 90 & \\
\hline & & Pain & $1,2,3,4,5,13,24,32,33$ & 72 & \\
\hline
\end{tabular}

RW Thatcher (1989, 1991, 2001, 2010), J. Zhang 2019

Brain waves: Detta, Theta; Alpha1; Alpha2; Beta1; Beta2; Beta3 and High Beta or Gamma

Evoked potentials: (Visual evoked potential-VEP, Auditory evoked potential-AEP, Somatosensory evoked potential-SSEP, Motor evoked potentials-MEP, and Steady-state evoked potential-SSEP

Time-locked EEG activity/Event-related Potentials (ERPS): Eariy left anterior negativity-ELAN, Error-related negativity-ERN, Late positive component-LPC, Lateralized readiness potential-LRP, Mismatch negativity-MMN, N100 (Visual N1 and Auditory N100), N170, N2pC, N200, N400, P3a, P3b, P200, P300 (neuroscience), P600

Brain Cortical reqions and their Function: Frontal lobe (thinking, planning, motor execution, executive function, mood control), Frontal lobe (thinking, planning, motor execution, executive function, mood control), Parietal lobe (Somatosensory-vision and somatospatial: information integration), Occipital lobe (visual perception and processing), Temporal lobe (language, auditory, long-term memory and emotion, Posterior cingulate gyrus (attention, long-term memory), Anterior cingulate gyrus (volitional movement, attention, long-term memory), and Parahippocampal gyrus (short-term memory, attention)

b

After I was released from the hospital (a week and a day after the fall) my physiatrist followed up regularly during the first month and adjusted exercises as needed. I had absence seizures and was on anticonvulsant medications until I was around 21 years old. I had regular blood work, electroencephalograms (EEGs), and follow-ups with neurologists and neurosurgeons to make sure everything was under control. The other sequela that lingered was short-term memory impairment. I continued to work on fine motor control for some time; after several months, I was playing the recorder and the flute again and even rejoined the orchestra.

Figure 4. (a) Current and potential EEG-based markers for both "TRACKING RECOVERY and brain RETRAINING". (b) Excerpts from a Case Study illustrating both the use of EEG in TBI treatment and what is possible when high-quality acute and post-acute care are provided, even after 5-hours delay in the identification of TBI. Taken from: Panel 6 "a patient's testimony"; Maas AIR et al, Lancet Neurol. 2017 [38]. In 1988, 12 year old, Laura E Gonzalez-Lara fell down an orchestra pit as she took part in a concert in a small town in Mexico and suffered a TBI. TBI identification and treatment commenced 5-hours after her injury. Gonzalez-Lara benefited from the support of her parents, both physicians, and extended family 


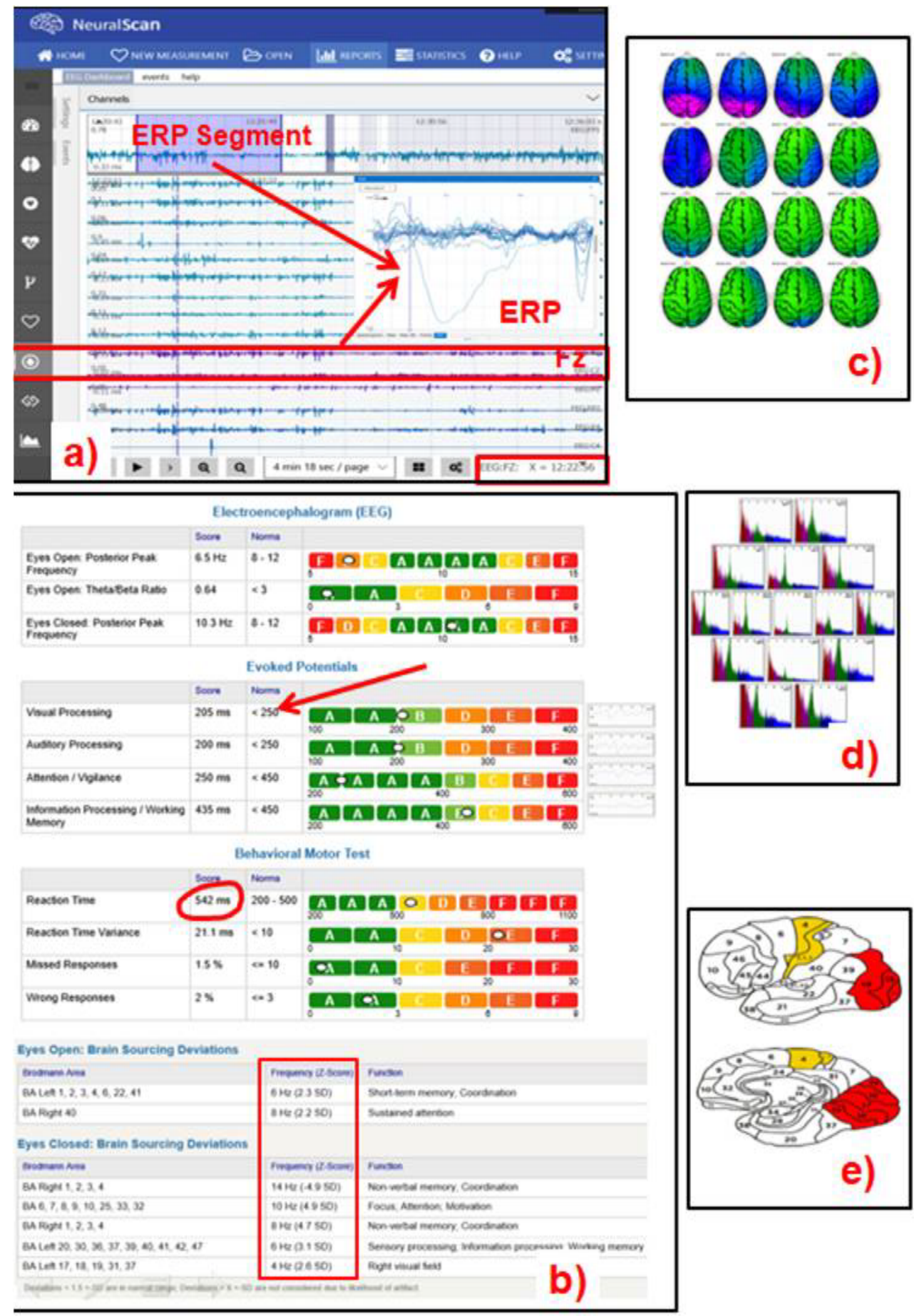

Figure 5. The potential of NeuralScan by Medeia in "TRACKING RECOVERY and brain RETRAINING" (Images of both features and reports that NeuralScan comes with; a)19-channel EEG tracing capturing ability, EEG tracing at rest, evoked potentials and event related potentials (ERP, b)Reports on visual and auditory processing, attention, working memory, reactiontime (RT), RT variance (RTV), missed and wrong responses, assessment of Broadmann areas in terms of their function ability, c) qEEG and topographical maps, d)time frequency analysis and e) identification of Broadmann areas affected) 
[51-56]. In a prospective multicenter study of severe TBI $(n=34)$ surface and invasive intracortical depth electroencephalography (EEG) was carried out [54]. Cerebral microdialysis was carried out simultaneously to measure lactate/pyruvate ratio a marker of metabolic crisis. NCSs or PDs occurred in $61 \% .42 .9 \%$ of the NCSs were only captured when intracortical depth EEG was used. The maximum duration of NCS was many hours. Disruption of cerebral metabolism was seen during NCS or PDs but not during electrically nonepileptic epochs [53]. NCS following TBI has also been correlated with hippocampal atrophy [55].

\section{EEG- based markers to classify TBI severity}

To classify the severity of TBI three parameters are required, the Glasgow Coma Score (GCS), duration of loss of consciousness (LOC) and duration of posttraumatic amnesia (PTA) [57-59]. However each parameter has its own technical difficulties ranging from the subjectivity and inter-rater variability of the GCS to patient being unaware of the exact time when consciousness or memory was lost and at times the GCS or LOC or PTA or all three were not obtained [58-60]. To make the classification of TBI severity more objective an EEG-based index of TBI severity was developed. The EEG's ability to identify blast concussions years later, in outpatients, mild TBI (following injury accuracy $95.67 \%$ with $>75.8 \%$ accuracy 1 -year after the injury) have been demonstrated [61-65].

In 1989 Thatcher demonstrated the EEGs ability to discriminated between mild TBI in a study of 608 mild TBI and 108 age-matched normal subjects (overall discriminant classification accuracy $=94.8 \%$ ) and cross-validated the findings in three separate independent study populations $[63,64]$. The EEG features associated with mechanical head injury were: "i)increased coherence and decreased phase in frontal and frontal-temporal regions; ii)decreased power differences between anterior and posterior cortical regions; and iii)reduced alpha power in posterior cortical regions" [65]. In a QEEG study of 91 subjects (32 mTBI with $<20$ minutes LOC, 9 TBi with $>20$ minutes LOC and 52 normal individuals) 1999 Thornton evaluated the robustness of these EEG variables at $>1$-year following TBI [66]. The high frequency discriminant developed by Thatcher classified the severity of $100 \%$ of TBI subjects at 1 -year post-TBI, $87 \%$ of subjects at all time periods and $79 \%$ of subjects 43 -years post injury. To derive the EEG index of TBI severity, 108 patients with closed TBI 15 days to 4 years after injury (mild TBI $n=40$, mild TBI $n=25$, and severe TBI $n=43$ ) were studied via eyes-closed resting EEG and power spectral analyses of 2- to 5-minute segments was done (19 electrodes, International 10/20 System, left ear lobe as reference). Discriminatory ability of the index of severity index developed from the EEG variables was between mild versus (vs) severe TBI groups was accuracy $=96.39 \%$, sensitivity $=95.45 \%$, and specificity $=97.44 \%$ and the $\mathrm{t}$-test showed significant difference between groups (Mild vs. Moderate, $\mathrm{p}<0.0001$; Mild vs. Severe, $\mathrm{p}<0.000001$; Moderate vs. Severe, $\mathrm{p}<0.00001)$ [65].

Naunheim and Neil took these findings further for two reasons; i) the incidence of TBI and mild TBI making computed tomography (CT) imaging in acute mTBI expensive and impractical, ii) $70 \%$ of individuals with TBI selected for CT using criteria like the New Orleans Criteria (NOC) were CT negative $[67,68]$. Naunheim validated the qEEG TBI severity index (specificity 90\%) in 105 TBI subjects (53 CT positive TBI discriminant index of 80.4 and 52 CT negative-TBI discriminant index of 38.9) and 50 healthy controls (TBI discriminant index of 24.5) [67]. Neil studied 119 patients with mTBI, the patients were screened using a) CT and b) qEEG, using the EEG-based index of TBI severity (0 minutes, eyes closed resting EEG with frontal electrodes FP1, FP2,
$\mathrm{AFz}, \mathrm{F} 7$, and F8, referenced to linked ears arranged according to the International 10/20 system) to determine if they required a CT or not. Using Marshall's criteria the subjects were then classified as CT positive or negative. TBI-Index and the NOC had sensitivities, at $94.7 \%$ and $92.1 \%$ respectively [68]. The specificity of the TBI-Index versus NOC was $49.4 \%$ versus $23.5 \%$, positive predictive value, negative predictive value and positive likelihood ratio were better with the TBI-Index, combining both indices increased sensitivity to obtain a positive CT result to $97 \%$. [68].

Predicting TBI outcomes and readiness to-return-to-play/ work/drive: In patients with moderate or severe TBI it can be used to guide assessment and treatment post-TBI (primary injury), for early identification of secondary injury if any, in recovery, prior to discharge and rehabilitation (Figure 3 ) in particular if neurocognitive therapy is required and in determining if the patient is ready to-return-to-play/ work/drive. Invasive continuous EEG (cEEG) is used in monitoring secondary brain injury [38].

Predicting TBI outcomes: Assessment of consciousness level is important in patients with TBI as it aids clinicians in treatment decision making. The bispectral index (BIS, ranging from 0: isoelectric signals to 100: conscious patients) originally used to measure the clinical state of anesthesia was evaluated in a study by Senapathi as a candidate marker of consciousness and sedation level in TBI patients $(n=78)$ with decreased consciousness. BIS value was highly correlated with GCS score $(r=0.744, p<0.01)$ in TBI patients [69]. Mean BIS values of mild, moderate, and severe head injury were $88.1 \pm 5.6,72.1 \pm 11.1$, and $60.4 \pm 11.7$, respectively. Further an equation to predict GCS from a BIS value derived using linear regression analysis: $\mathrm{GCS}=0.21$ (BIS) -5.208 . Mahadewa assessed the correlation between Glasgow Outcome ScaleExtended (GOS-E) scores calculated 6 months after the TBI event with BIS values on admission in $68 \mathrm{TBI}$ patients who underwent craniotomy, correlation was at $r=0.921, p<0.01$ (70). Findings suggest that BIS scores upon admission may be used to predict the outcomes in patients with TBI. An equation to predict GOS-E from BIS value derived from the linear regression analysis in this study, and this is GOS-E $=0.19$ (BIS) $-8.3[70]$.

EEG features of worse outcome following a TBI include lower (regional) EEG power, slowing of the EEG decrease in alpha power, lower EEG (alpha) variability, and increased coherence [50,63,71-78]. A recent study by Haveman used multifactorial Random Forest models and qEEG parameters to predict outcome in 57 patients (training set; $n=38$ and a validation set; $n=19$ ) with moderate to severe TBI [78]. Outcome at 12 months by the Extended Glasgow Outcome Score (GOSE) was categorized as poor (GOSE 1-2) or good (GOSE 3-8). Twenty-three qEEG features were extracted to develop the multifactorial Random Forest model which was compared with the International Mission for Prognosis and Clinical Trial Design (IMPACT) predictor in its ability to predict outcomes via GOSE. The predictive ability of the new model was evaluated using leave-one-out (area under the receiver operating characteristic curve-AUC for the training set was AUC $=0.94$, (specificity $100 \%$, sensitivity $75 \%$ ) and validation set $\mathrm{AUC}=0.81$, (specificity 75\%, sensitivity 100\%). The IMPACT predictor had an AUC of 0.74 (specificity $81 \%$, sensitivity $65 \%$ ) and 0.84 (sensitivity $88 \%$, specificity $73 \%)$, respectively.

Monitoring cortical spreading depolarizations: Another feature occurring following a TBI and warranting monitoring is cortical spreading depolarizations which are associated with worse prognosis. The neuropathophysiology behind this feature is that cortical spreading 
depressions, or propagating waves of astrocyte depolarization have been linked with the neuropathological cascade that characterizes secondary injury [43-45,56-63].

Determining readiness to-return-to-play/work/drive: In the interest of brevity we will briefly discuss EEGs potential to determine readiness to-return-to-play/work/drive using sports-related-injury as a classic example. Following mTBI symptoms and in the clinical recovery stage of moderate and severe TBI while symptoms resolve it is imperative that the brain is allowed sufficient time to heal. Athletes/ coaches/military personnel tend to underreport symptoms due to personal goals, pressure and desire not to let down teammates. Sustaining multiple concussions before the brain has had time to heal has revealed an excess of amyloid-beta plaques and tau tangles in autopsies of football players, possibility of chronic traumatic encephalopathy (CTE) dementia, mental health issues, and depression [79]. A brain recovery can extend beyond the clinical recovery time, so an improved neurological function index is needed [79-82]. Post-TBI symptoms can last from 1-month to 3-months,and can even become chronic (even in mTBI-15\%) when microstructure white matter lesions are present and fail to heal [83-86].

McCrea studied the clinical utility of the EEG from injury to recovery (eg: Figures 1 and 5) in a prospective, non-randomized study of 396 high school and college football players, including a subset of 28 athletes with concussion and 28 matched controls. Baseline measures of postconcussive symptoms, postural stability, cognitive functioning, and qEEG (preseason) were obtained [87]. On injury, qEEG, neurocognitive tests and symptom recording were carried out on day-Injury, day-8 and day-45 in the injured and control group. Results for the injured group were: day-injury: symptoms present till day-3, neurocognitive testing: results were poor and qEEG: showed abnormalities. Day-8: symptoms resolved, neurocognitive testing: return to baseline and qEEG: showed abnormalities. Day-45: symptoms resolved, neurocognitive testing: return to baseline and qEEG: return to baseline [87]. Another study by Barr on 59 athletes with TBI and 31 controls using qEEG to track injury and recovery on day-injury, day- 8 and day- 45 also yielded similar results [88]. The findings indicated that EEG abnormalities persist past clinical recovery and symptom resolution and are suggestive that return-toplay decisions are based on EEG patterns returning to baseline $[89,90]$.

To increase the objectivity of the return-to or remove-from play decision and keeping the above findings in mind McNerney developed a scoring system combining both EEG and symptom questionnaires [91]. 38 individuals with mTBI and 47 controls were administered a symptom questionnaire, behavioral tests, and resting state EEG was measured [91-95]. 12 EEG variables were recorded (delta, theta, alpha, beta, sigma, and gamma bands from the A7-FpZ and A8-FpZ voltages). Accuracy was $75-82 \%$ when only symptoms were used to predict return-to-play, while EEG in combination with three-symptoms had an accuracy of $91 \%$.

Assessment of coma, clinical recovery of consciousness and cognitive function: In patients presenting either at trauma site or at the ED who are unconscious/ in a coma and therefore assessment using verbal commands is futile triaging can classification of severity of TBI can be achieved and the depth of coma assessed using EEG. In comatose patients in a vegetative state it can be used in decision making regarding when life saving measures are futile. Three EEG features have been considered as prognostic indicators of recovery of consciousness, they include sleep spindles (hallmark of stage-2 sleep, absent in coma) $(96,97)$, EEG reactivity (EEG-R, the EEG response to external stimulation) and EEG-awakening (a combination of EEG-R and sleep spindles). 106 individuals in a coma for $>3$ days were followed for 1 month, receiving operator curve (ROC) analysis revealed EEGawakening $(0.839 ; 0.757-0.921)$ to be the best prognostic indicator of recovery from consciousness followed by EEG-R $(0.798 ; 0.710-0.886)$, sleep spindles $(0.772 ; 0.680-0.864)$, and Glasgow Coma Score (GCS) scores $(0.720 ; 0.623-0.818)$. ERPs involved in predicting awakening N100, mismatch negativity (MMN), and P300, is a highly significant predictor for awakening [96-99]. The absence of the somatosensoryevoked potential (SSEP) N2 in comatose patients has traditionally been regarded as a good indicator for the likelihood of non-awakening [100]. However, its presence does not guarantee recovery of consciousness $[101,102]$.

Declaration of brain death: It can and is used in deciding if a patient is brain dead particularly in instances where organ donation is being considered by the next of kin.

Since brain death (BD) was first defined as "coma dépassé" there have been several efforts to reach a global consensus on best practices to be followed when declaring $\mathrm{BD}$ especially in view of organ transplantation [103-107]. Neurosurgeons and neurologists when surveyed about the standard best and objective $\mathrm{BD}$ declaration practices they followed $65 \%$ mentioned they required an isoelectric EEG; $29 \%$ needed only one EEG while $36 \%$ required two EEGs, 24 hours apart [108]. In order to increase the objectivity of BD declaration each test used has specific guidelines. EEG guidelines recommend use of a 16 channel, 10-20 system, 30 minute EEG recording, with auditory and bilateral somatosensory stimuli (touch and pain) repeatedly performed and clearly marked10,12 on the recording, with the time interval between the two EEGs dictated by age of the patient $[109,110]$.

Metal shrapnel: In gunshot wounds (GSW) and blasts where metal shrapnel prevents assessment via neuroimaging (MRI and CT). In TBI caused by blasts and GSW the primary injury suffered by the individual is composed of injury due to the event, further injury by penetrating metallic shrapnel, the velocity with which the bullet is fired or the individual is thrown due to the blast and the injury caused as the individual falls (height of the fall and the surface texture on which the individual lands) $[111,112]$. Evaluating the severity of the injury using magnetic resonance imaging (MRI) warrants caution as the powerful magnet may cause further injury. In such instances EEG to assess TBI severity and TBI location via LORETA appears beneficial [111,112].

Malingering: Healthcare personnel and insurance companies use the EEG to ascertain if symptoms/complaints reported are due to current or previous TBI or other neurocognitive or neuorodegenerative disorders or malingering.

"Malingerers are individuals in who symptoms are consciously produced (either exaggerated or fabricated) to achieve their internal eg: achieving the sick role, when being evaluated for disability pensions or monetary compensation for damages sustained in accidents". 40\% of mTBI individuals undergoing evaluations may be malingerers [113]. Tests carried out to evaluate malingered neurocognitive deficit (MNCD) include the Test of Memory Malingering (TOMM), tests capturing the evaluee's responses involving aspects that are under less conscious control, such as reaction time (RT) and brain activity using electroencephalograph (EEG). Malingering evaluees have slower RTs than both normal and brain injured control groups; [114]. Their RT patterns also differ resulting in a cognitive phenomenon, the "Stroop Effect" [115]. Findings were that honest $(\mathrm{HON})$ normals and brain injured patients exhibited the Stroop effect, whereas malingerers 
(uninformed/coached) exhibited an inverted Stroop effect. As TBI causes changes in EEG patterns, it in turn impacts on ERP markers of cognitive functions, including processing speed, sustained attention, performance monitoring, inhibitory control, and cognitive flexibility [116]. Among the ERP markers, the P3a can differentiate between those with TBI and malingerers [117].

In a malingered neurocognitive deficit (MNCD) study by Vagnini, 32 normal individuals (honest-HON; $\mathrm{n}=16$ ), normal individuals instructed to behave as malingerers (MAL; $\mathrm{n}=16$ ) as 15 patients with (TBI) were administered the Test of Memory Malingering (TOMM) and the Old-New Task test [118]. The time intervals examined for ERPs were N1, P1, N2, P2, N3, P3 etc. Comparison of the mean ERP amplitude values for each group suggested that $\mathrm{HON}$ and TBI showed the typical ERP Old-New effect while MAL differed. The effect for the Old-New task was intact for HON, reduced but trending towards significant in TBI, and absent in MAL. The differences between ERPs for frontal vs. posterior electrodes, HON had the strongest activity in the frontal area, for those with TBI strongest activity was in the posterior area, and MAL showed no significant difference between frontal and posterior activity. The frontal-posterior difference might be an effective indicator to identify malingerers.

In another study carried out by Neal latencies of memory-related brain potentials (sensitivity of $80 \%$ and specificity of $79 \%$ ) were compared among individuals with moderate or severe TBI $(n=14)$, and healthy age-matched individuals (honest; $\mathrm{n}=12$ or faking memory deficit; $n=15$ ) [119]. Test of Memory Malingering (TOMM) and the Old-New Task test were used [57,58,120-126]. Bilateral fractional latencies of the ERP, P3a at frontal sites were averaged latencies $=396$ $\mathrm{ms}$ malingerers and averaged latencies $=312 \mathrm{~ms}$ for true TBI in the frontal sites. Only malingerers showed asymmetrical frontal activity compared to the two other groups [120-126].

Challenges of EEG-based assessment of TBI: In mild TBI, 86\% with an abnormal neurological examination have an abnormal EEG while only $23 \%$ of individuals with abnormal EEGs were abnormal on neurological examination [127-133]. These findings have been attributed to the order in which the brain heals; first symptom resolution, second clinical recovery and finally EEG patterns returning to normal. EEG abnormalities are more commonly seen in patients with durations of unconsciousness lasting more than 2 minutes (56\%) than in patients with briefer periods of unconsciousness (17\%) (127-133). EEG changes vary with individuals, the severity of head injury and changes in an EEG following a TBI can be restored to baseline as early as 15 minutes after concussion [127-133].

EEG-based markers to evaluate post-trauma neurocognitive ability: Assessment of cognitive impairment following a TBI ranges from evaluating pre-existing and new knowledge (acquisition and comprehension), attention, memory and working memory, judgment and evaluation, reasoning and "computation", problem solving, decision-making, comprehension, production of language, temporal organization, conflict management, to cognitive and psychological (personality changes, impairments in processing social cues, emotions and in communication) aspects of behavioural disorders [134-157]. These cognitive issues together with accident phobia contribute to poor-quality of life, social and vocational outcomes following TBI account for 0.85 million requiring long-term rehabilitation and care in the United States [152,154-158].

Many of the cognitive impairments seen are attributed to EEG spectral changes [159-161]. Even mTBI is known to lead to EEG- detectable changes in brainwave patterns, connectivity, coherence, power and amplitude [65] and in neuronal network dysfunction $[162,163]$. Rapp in a review of 25 qEEG studies on mTBI found that though decrease in alpha power and increase in delta, beta, and theta power was often reported study findings varied greatly the first difference being attributed to differences in study aims and methodologies and the second due to the fact that no two TBI are the same. For example, only three of the 25 studies examined functional connectivity and coherence in mTBI and 9 studies examined the discriminatory ability of EEG in mTBI. O'Neil's study on EEGs discriminatory ability did not compare its ability to distinguish between mTBI versus controls instead the study examined sensitivity of the TBI-Index (94.7\%) versus the New Orleans Criteria (NOC) and the TBI-index-plus-NOC (97\%) in determining which patient with mTBI required a CT and which did not [68]. Evoked potentials (EP) both short and middle latency are used to predict coma outcomes and awakening in TBI while long-latency EPs are used to predict recovery of higher level cognitive function $[92,153,164]$. ERP associated with sensation (N100); perception (MMN); attention (P300), memory for own name (Early Negative Enhancement to Sound of Own Name); and comprehension (N400) are also used to differentiate between TBI and healthy controls. ERPs used to monitor cognitive impairment following TBI include:

a) The error-negativity/error-related negativity (Ne/ERN) and posterror positivity $(\mathrm{Pe})$ used to evaluative control/performance monitoring $[165,166]$.

b) Feedback-related negativity (FRN) is evoked following performance or response feedback, with a larger FRN indicating unfavourable outcome [165].

c) P300 amplitude and latency

d) Elicited using colours (red, green or darkness affect) is used to evaluate cognition and emotion post-TBI $[167,168]$.

e) P300 elicited using images capturing facial cues is used to evaluate social behavior $[155,163]$. In a study of 13 individuals with moderate to severe TBI and 13 healthy controls P300 was measured following presenting of 30 pictures of angry faces and 120 pictures of neutral faces. TBI versus (vs) controls had a P300 latency of $486 \mathrm{~ms}$ vs 416 $\mathrm{ms}(\mathrm{p}<0.005)$, amplitude of $11.3 \mu \mathrm{V}$ vs $19.1 \mu \mathrm{V}(\mathrm{p}<0.005)$ and reaction time of $653 \mathrm{~ms}$ vs $443 \mathrm{~ms}(\mathrm{p}<0.005)$. Results indicate that following TBI patients had difficulty in detecting facial cues.

f) P300 amplitude and latency is correlated with duration of posttraumatic amnesia [169].

g) P300 elicited via three-stimulus oddball tasks demonstrated a decrease/suppression (in $\mathrm{N} 2$ and P3b amplitudes) in subjects $\geq 3$ years post-concussion compared to healthy controls and among multi-concussion athletes [136].

h) Gosselin in a study of 44 individuals with mTBI and 40 controls evaluated frontal: N200 and N350 and parietal: P200 and P300 amplitude and latency [139]. The propelling fact for the study was that $15 \%$ of individuals with sports related concussions/mTBI have persistent cognitive problems. The study examined working memory (WM) post-mTBI due to a motor vehicle accident (MVA) or sports injury. Chief findings were mTBI versus controls had significantly ( $\mathrm{p}$ $<0.05$ ) smaller amplitudes of both frontal N350 and parietal P300 and worse $(\mathrm{p}<0.05)$ accuracy on WM task.

i) Auditory evoked potential (AEP) and visual evoked potential (VEP) stimuli (including facial affective stimuli) can differentiate between 
healthy controls and TBI individuals and can be used to evaluate attention, detect emotion, and cognitive function [169-173].

j) Mismatch negativity (MMN) is used to evaluate automatic attentional processes and information processing. MMN is used to differentiate vegetative state from minimal conscientious state and in in predicting coma outcomes from coma [174,175]. The Halifax Consciousness Scanner (HCS) paradigm and the P300 are used to evaluate conscious awareness level [176]. Following severe TBI conscious awareness is often compromised which is usually using behavioral responses. In order to obtain a more objective idea of the patient's conscious awareness level a semi-automated electroencephalography system (HCS) was designed and evaluated in 28 sTBI patients and 100 healthy controls. Here to P300 latencies correlated significantly $(\mathrm{p}<0.05)$ with sTBI versus controls as well as with the clinical assessment scores.

Visually evoked stimulus at $750 \mathrm{msec}$ post-stimulus is used to evaluate word retrieval which requires precise interactions between different brain regions [144]. In a study on word retrieval in 19 retired professional athletes with TBI and 19 healthy controls, both groups did not differ in accuracy or reaction time, however healthy controls showed significant differences between retrieval and non-retrieval conditions (between $750 \mathrm{msec}$ to $1000 \mathrm{msec}$ ) while individuals following TBI showed no such difference [144].

Sleep disorders after TBI: Sleep disorders (hypersomnia, insomnia, parasomnia, daytime somnolence, changes in sleep patterns, sleep-wake schedule and deranged sleep architecture) common in TBI patients compromise rehabilitation and return-to-work. Their timely diagnosis and treatment will help facilitate the rehabilitation process [177]. Urakami studied the spindle activity in acute, sub-acute, and chronic stages of posttraumatic coma and in 60 adult patients following diffuse axonal injuries (DAI), with sleep-related complaints 3 months to 2 years following TBI [178-180]. Findings include; the four source where spindle activation occurs included the precentral (slow spindles seen) and post-central (fast spindles seen) areas in posterior frontal cortex (PFC) and parietal cortex of each hemisphere. When spindle distribution was symmetrically in amplitude all four cortical areas were activated. However, when spindles exhibited an asymmetric distribution with an amplitude differences of $>30 \%$ between the hemispheres then temporal activation occurred. In the postacute stage (mean 80 days) frequency, amplitude, cortical activation source strength of spindle activities was significantly decreased while in the chronic stage (mean 151 days), spindles significantly increased, and no significant difference was found between normal subjects [180]. Cognitive functions also improved, with favorable 1-year outcome [179].

\section{EEG patterns, neural connectivity and $\mathrm{Z}$ score biofeedback neurofeedback}

In a study of gray matter-white matter normal control $(n=25)$ subjects exhibited bimodal while TBI patients $(n=31)$ exhibited unimodal gray matter-white matter histograms. More importantly while pixels of intermediate intensity (between grey and white matter) were at the border in controls, intermediate pixels were found both at the borders and in between grey and white matter in TBI subjects [181]. Functional impairments of the brain have been found to exist due to these and other changes in connectivity and network pathology $[181,182]$. The brain is thought to be composed of small-clusters with all clusters involved in a particular function interconnected in a manner that ensures optimum information processing [183]. Another theory it that the brain is both segregated into distinct regions based on function and yet it is integrated at the global level in order to promote information processing $[183,184]$ with the prefrontal, frontal, and central sites all networked to ensure working memory (WM) and speed of information processing [185]. Specific functional networks exist for anxiety, language, memory, mood and pain [186-210]. The prefrontal cortex (PFC) is involved in working memory tasks, supplementary motor area (SMA) and anterior cingulate cortex (ACC) are implicated in "vocal-motor planning", the primary motor cortex (PMC) and SMA in movement and the "default network" in resting and contemplative states [211-219].

White matter (high speed relay system) when damaged following a TBI results in slower delta and at times even theta waves emerging [220-223]. Hypercoherence or hypocoherence is also seen depending on the damage following TBI. Gray matter (high plasticity) damage may initially cause spectral changes (increase in alpha causing cortical idling) but with time and healing the changes may return to ear normal (beta followed by gamma indicating active networks) [220-223]. The return to near normal of brain waves patterns can be stimulated by cognitivebehavioral/neurofeedback/ physical therapy interventions [224]. Transcranial magnetic stimulation (TMS), is a promising new tool used in treatment of TBIs like diffuse axonal injury (DAI) which account for $40 \%$ individuals with severe TBI [225-232]. Neurofeedback involves first identifying functional networks in the brain associated with a patients symptoms and then stimulating the impaired functional network [233238]. A recent method used in EEG Neurofeedback is called $Z$-Score Neurofeedback here post-TBI individuals with symptoms/complaints are first compared with an age-matched population of healthy subjects to identify hubs and networks are unstable or dysregulated [233-238]. Using operant conditioning and reinforcement brain wave patterns in regions corresponding to the symptoms are stimulated until they go from exhibiting outlier patterns to closer to near normal Z-score patterns thus restoring equilibrium, increasing efficiency and the brain network and processing speed [233-238].

One review on EEG- and ERP-based markers of TBI found processing speed to be 1.54 times slower in TBI patients. Impaired perceptual and psychomotor processes were also observed [239]. P300 latency were found to reflect stimulus-processing time while contingent negative variation $(\mathrm{CNV})$ reflected response-processing time. Following TBI impairment in processing of warning cues resulted in increased P2, N2 and P3 latencies as well as impaired attention to the warning cues indicated via reduced P2 amplitude compared to controls. As sustained attention is often a problem post-TBI one study used long-term focused attention (FA) meditation training to increase theta band consistency improving attention. The review also looked at ERP markers of performance monitoring, inhibitory control and cognitive flexibility following a TBI [239]. Another review focused on visual and auditory evoked ERPs. ERPs examined and elicited via visual or auditory odd-ball paradigms were N2, N350, and P3 i.e. P3a/ P3b components. The characteristic amplitude reduction and latency increase pattern was seen among mTBI patients [240-242].

\section{Conclusion}

Traumatic brain injury (TBI) is a major health concern in terms of morbidity, impact on the work force, family life and income, disability, cognitive issues and mortality it causes. Electroencelaphalographs (EEG) like NeuralScan are essential tools at specific crossroads in TBI evaluation, management, treatment and rehabilitation (like predicting seizures post-trauma, defining severity of current and previous TBI, identifying malingerers, predicting TBI or coma outcomes, and 
Z-score training via Neurofeedback).The added benefit of machines like Neuralscan in TBI treatment are that they are clinician friendly, versatile, reliable, robust, portable and cost-effective allowing for use at the site of the injury, in transit, for continuous monitoring (stationary and ambulatory) allowing for evaluation of brain wave patterns, EPs, ERPs, qEEG, topographical maps and frequency analysis, LORETA based source analysis and neurofeedback.

\section{References}

1. James SL (2019) GBD 2016 Traumatic Brain Injury and Spinal Cord Injury Collaborators. Global, regional, and national burden of traumatic brain injury and spinal cord injury, 1990-2016: a systematic analysis for the Global Burden of Disease Study 2016. Lancet Neurol 18: 56-87.

2. Dewan MC, Rattani A, Gupta S, Baticulon RE, Hung YC, et al. (2018) Estimating the global incidence of traumatic brain injury. J Neurosurg 1: 1-18. [Crossref]

3. Bener A, Omar AOK, Ahmad AE, Al-Mulla FH, Abdul Rahman YS: The pattern of traumatic brain injuries: a country undergoing rapid development. Brain Inj 24: 74-80.

4. The changing landscape of traumatic brain injury research. Lancet Neurol 11: 651.

5. Roozenbeek B, Maas AI, Menon DK (2013) Changing patterns in the epidemiology of traumatic brain injury. Nat Rev Neurol 9: 231-236. [Crossref]

6. Chiu WT, Huang SJ, Tsai SH, Lin JW, Tsai MD, et al. (20170 The impact of time, legislation, and geography on the epidemiology of traumatic brain injury. $J$ Clin Neurosci 14: 930-935.

7. Ji C, Duan L, Wang L, Wu C, Wang Y, et al. (2015) Study on head injuries through data from the National Injury Surveillance System of China, 2013. Zhonghua Liu Xing Bing Xue Za Zhi. 36: 360-363. [Crossref]

8. Selassie AW, Wilson DA, Pickelsimer EE, Voronca DC, Williams NR, et al. (2013) Incidence of sport-related traumatic brain injury and risk factors of severity: a population based epidemiologic study. Ann Epidemiol 23: 750-756.

9. Siman-Tov M, Radomislensky I, Knoller N, Bahouth H, Kessel B, et al. (2016) Incidence and injury characteristics of traumatic brain injury: comparison between children, adults and seniors in Israel. Brain Inj 30: 83-89. [Crossref]

10. Szarpak $Ł$, Madziała M (2011) Epidemiology of cranio-cerebral injuries in emergency medical services practice. Pol Przegl Chir 83: 646-651.

11. Sharp DJ, Jenkins PO (2015) Concussion is confusing us all. Pract Neurol 15: 172-86.

12. Andriessen TM, Horn J, Franschman G (2011) Epidemiology, severity classification, and outcome of moderate and severe traumatic brain injury: a prospective multicenter study. J Neurotrauma 28: 2019-2031.

13. Vitaz TW, Jenks J, Raque GH (2003) Outcome following moderate traumatic brain injury. Surg Neurol 60: 285-291.

14. Shafiei E, Fakharian E, Omidi A (2016) Effect of Mild Traumatic Brain Injury and Demographic Factors on Psychological Outcome. Arch Trauma Res 5: e29729.

15. Stein SC, Georgoff P, Meghan S (2010) Relationship of aggressive monitoring and treatment to improved outcomes in severe traumatic brain injury. J Neurosurg 112: $1105-1112$.

16. Watanitanon A, Lyons VH, Lele AV (2018) Clinical Epidemiology of Adults with Moderate Traumatic Brain Injury. Crit Care Med 46: 781-787.

17. Daneshvar DH, Nowinski CJ, Cantu R (2011) The epidemiology of sport-related concussion. Clin Sports Med 30: 1-17. [Crossref]

18. Langlois JA, Rutland-Brown W, Wald MM (2006) The epidemiology and impact of traumatic brain injury: a brief overview. J Head Trauma Rehabil 21: 375-378.

19. Bell RS, Vo AH, Neal CJ, Tigno J, Roberts R, et al. (2009) Military traumatic brain and spinal column injury: a 5-year study of the impact blast and other military grade weaponry on the central nervous system. J Trauma 66: S104-S111. [Crossref]

20. Terrio H, Brenner LA, Ivins BJ, Cho JM, Helmick K, et al. (2009) Traumatic brain injury screening: preliminary findings in a US Army Brigade Combat Team. J Head Trauma Rehabil 24: 14-23.

21. Rabinowitz AR, Levin HS (2014) Cognitive sequelae of traumatic brain injury. Psychiatr Clin North Am 37: 1-11. [Crossref]

22. DeGuise E, LeBlanc J, Feyz M, Meyer K, Duplantie J, et al. (2008) Long-term outcome after severe traumatic brain injury: the McGill interdisciplinary prospective study. $J$ Head Trauma Rehabil 23: 294-303.
23. Arciniegas DB, Wortzel HS (2014) Emotional and behavioral dyscontrol after traumatic brain injury. Psychiatr Clin North Am 37: 31-53.

24. De Guise E, LeBlanc J, Feyz M, Lamoureux J (2006) Prediction of outcome at discharge from acute care following traumatic brain injury. J Head Trauma Rehabil 21: 527-536

25. Rassovsky Y, Levi Y, Agranov E, Sela-Kaufman M, Sverdlik A, et al. (2015) Predicting long-term outcome following traumatic brain injury (TBI). J Clin Exp Neuropsychol 37: 354-366.

26. Whiteneck GG, Gerhart KA, Cusick CP (2004) Identifying environmental factors that influence the outcomes of people with traumatic brain injury. J Head Trauma Rehabil 19: 191-204.

27. Luukinen H, Viramo P, Koski K, Laippala P, Kivela SL, et al. (1999) Head injuries and cognitive decline among older adults: a population-based study. Neurology 52: 557-562.

28. Mosenthal AC, Lavery RF, Addis M, Kaul S, Ross S, et al. (2002) Isolated traumatic brain injury: age is an independent predictor of mortality and early outcome. J Trauma 52: 907-911.

29. Susman M, DiRusso SM, Sullivan T, Risucci D, Nealon P, et al. (2002) Traumatic brain injury in the elderly: increased mortality and worse functional outcome at discharge despite lower injury severity. $J$ Trauma 53: 219-223. [Crossref]

30. Gardner RC, Byers AL, Barnes DE, Li Y, Boscardin J, et al. (2018) Mild TBI and risk of Parkinson disease: A Chronic Effects of Neurotrauma Consortium Study. Neurology 90: e1771-e1779.

31. Julien J, Joubert S, Ferland MC, Frenette LC, Boudreau-Duhaime MM, et al. (2017) Association of traumatic brain injury and Alzheimer disease onset: A systematic review. Ann Phys Rehabil Med 60: 347-356.

32. Galgano M, Toshkezi G, Qiu X, Russell T, Chin L, et al. (2017) Traumatic Brain Injury: Current Treatment Strategies and Future Endeavors. Cell Transplant 26: 1118-1130. [Crossref]

33. American Academy of Neurology Clinical Practice Guideline Process Manual, 2004 ed St. Paul, MN: The American Academy of Neurology; 2004

34. American Academy of Neurology Clinical Practice Guideline Process Manual, 2011 ed St. Paul, MN: The American Academy of Neurology; 2011

35. Giza CC, Kutcher JS, Ashwal S (2013) Summary of evidence-based guideline update: evaluation and management of concussion in sports: report of the Guideline Development Subcommittee of the American Academy of Neurology. Neurology 80: 2250-2257. [Crossref]

36. National Clinical Guideline Centre (UK). Head Injury: Triage, Assessment, Investigation and Early Management of Head Injury in Children, Young People and Adults. London: National Institute for Health and Care Excellence (UK); 2014 Jan (NICE Clinical Guidelines, No. 176.) Available from: https://www.ncbi.nlm.nih.gov/ books/NBK248061/. Accessed February 10, 2020.

37. Marehbian J, Muehlschlegel S, Edlow BL, Hinson HE, Hwang DY, et al. (2017) Medical Management of the Severe Traumatic Brain Injury Patient. Neurocrit Care 27: 430-446.

38. Maas AIR, Menon DK, Adelson PD, Andelic N, Bell MJ, et al. (2017) InTBIR Participants and Investigators. Traumatic brain injury: integrated to improve prevention, clinical care, and research. Lancet Neurol 16: 987-1048. [Crossref]

39. Setnik L, Bazarian JJ (2007) The characteristics of patients who do not seek medical treatment for traumatic brain injury. Brain Inj 21: 1-9.

40. Iaccarino M (2018) Mild Traumatic Brain Injury: A Clarion Call for Care of the Postconcussive Spectrum. JAMA Netw Open 1: e180211.

41. Seabury SA, Gaudette É, Goldman DP, Markowitz AJ, Brooks J, et al. (2018) Assessment of Follow-up Care After Emergency Department Presentation for Mild Traumatic Brain Injury and Concussion: Results From the TRACK-TBI Study. JAMA Netw Open 1: e180210.

42. Demakis GJ, Rimland CA (2010) Untreated mild traumatic brain injury in a young adult population. Arch Clin Neuropsychol 25: 191-196. [Crossref]

43. Institute of Medicine. "3 Understanding Pathophysiological Changes." 2011. Nutrition and Traumatic Brain Injury: Improving Acute and Subacute Health Outcomes in Military Personnel. Washington, DC: The National Academies Press.

44. Jain KK (2008) Neuroprotection in traumatic brain injury. Drug Discovery Today 13 1082-1089.

45. Kaur P, Sharma S (2018) Recent Advances in Pathophysiology of Traumatic Brain Injury. Curr Neuropharmacol 16: 1224-1238. 
46. Ruet A, Bayen E, Jourdan C, Ghout I, Meaude L, et al. (2019) A Detailed Overview of Long-Term Outcomes in Severe Traumatic Brain Injury Eight Years Post-injury. Front Neurol 10: 120.

47. Jochems D, van Wessem KJP, Houwert RM, et al. (2018) Outcome in Patients with Isolated Moderate to Severe Traumatic Brain Injury. Critical Care Research and Practice 18: 3769418.

48. One and Five Year Outcomes After Moderate-to-Severe Traumatic Brain Injury Requiring Inpatient Rehabilitation. TRAUMATIC BRAIN INJURY REPORT CDC https://www.cdc.gov/traumaticbraininjury/pdf/CDC-NIDILRR-Self-Report-508.pdf. Accessed February 10, 2020.

49. Wang KK, Yang Z, Zhu T, et al. (2018) An update on diagnostic and prognostic biomarkers for traumatic brain injury. Expert Rev Mol Diagn 18: 165-180. [Crossref]

50. Williams D (1941) The electro-encephalogram in acute head injuries. J Neurol Psychiatry 1941: 107-130.

51. Vespa PM, Nuwer MR, Nenov V, et al. (1999) Increased incidence and impact of nonconvulsive and convulsive seizures after traumatic brain injury as detected by continuous electroencephalographic monitoring. J Neurosurg 91: 750-760.

52. Stein NR, McArthur DL, Etchepare M, Vespa PM (2012) Early cerebral metabolic crisis after TBI influences outcome despite adequate hemodynamic resuscitation. Neurocritical Care 17: 49-57.

53. Vespa P, Tubi M, Claassen J (2016) Metabolic crisis occurs with seizures and periodic discharges after brain trauma. Annals of Neurology 79: 579-590. [Crossref]

54. Vespa P (2005) Continuous EEG monitoring for the detection of seizures in traumatic brain injury, infarction, and intracerebral hemorrhage: "to detect and protect" Journal of clinical neurophysiology 22: 99-106.

55. Vespa PM, Xu Y, Hovda D (2010) Nonconvulsive seizures after traumatic brain injury are associated with hippocampal atrophy. Neurology 75: 792-798. [Crossref]

56. Hartings JA, Watanabe T, Bullock MR (2011) Spreading depolarizations have prolonged direct current shifts and are associated with poor outcome in brain trauma. Brain 134: 1529-1540.

57. Teasdale G, Jennett B (1974) Assessment of coma and impaired consciousness: a practical scale. Lancet ii:81-84

58. Jennett B (1986) Head trauma, in Diseases of the Nervous System, edited by Asbury AK, McKhaan GM, McDonald WI. Philadelphia, WB Saunders 1282-1291

59. Pal J, Brown R, Fleiszer D (1989) The value of the Glasgow Coma Scale and injury severity score: predicting outcome in multiple trauma patients with head injury. $J$ Trauma 29: 746- 748. [Crossref]

60. Green SM (2011) Cheerio, laddie! Bidding farewell to the Glasgow Coma Scale. Ann Emerg Med 58: 427-430.

61. Trudeau DL, Anderson J, Hansen LM (1998) Findings of mild traumatic brain injury in combat veterans with PTSD and a history of blast concussion. J Neuropsychiatry Clin Neurosci 10: 308-313.

62. Hoffman DA, Stockdale S, Hicks L (1995) Diagnosis and treatment of head injury Journal of Neurotherapy 1: 14-21.

63. Thatcher RW, Walker RA, Gerson I (1989) EEG discriminant analyses of mild head trauma. Electroencephalogr Clin Neurophysiol 73: 93-106.

64. Thatcher RW, Cantor, DS, McAlaster R (1991) Comprehensive predictions of outcome in closed head injury: the development of prognostic equations. Ann NY Acad Sci 620: 82-104.

65. Thatcher RW, North DM, Curtin RT, Walker RA, Biver CJ, et al. (2001) An EEG severity index of traumatic brain injury. J Neuropsychiatry Clin Neurosci 13: 77-87.

66. Thornton KE (1999) Exploratory investigation into mild brain injury and discriminant analysis with high frequency bands (32-64 Hz). Brain Inj 13: 477-88. [Crossref]

67. Naunheim RS, Treaster M, English J, Casner T, Chabot R, et al. (2010) Use of brain electrical activity to quantify traumatic brain injury in the emergency department. Brain Inj 24: 1324-1329.

68. O'Neil B, Prichep LS, Naunheim R, Chabot R (2012) Quantitative brain electrical activity in the initial screening of mild traumatic brain injuries. West J Emerg Med 13: 394-400.

69. Senapathi TGA, Wiryana M, Aribawa IGNM, Ryalino C (2017) Bispectral index value correlates with Glasgow Coma Scale in traumatic brain injury patients. Open Access Emerg Med 9: 43-46.
70. Mahadewa TGB, Senapathi TGA, Wiryana M, Aribawa IGNM, Arparitna KY, et al (2018) Extended Glasgow Outcome Scale correlates with bispectral index in traumatic brain injury patients who underwent craniotomy. Open Access Emerg Med 10: 71-74.

71. Tolonen A, Särkelä MOK, Takala RSK, Katila A, Frantzén J, et al. (2018) Quantitative EEG parameters for prediction of outcome in severe traumatic brain injury: development study. Clin EEG Neurosci 49: 248-257. [Crossref]

72. Jasper HH, Kershman J, Elvidge A (1940) Electroencephalographic studies of injury to the head. Arch Neurol Psychiatr 44: 328-350.

73. Moulton RJ, Marmarou A, Ronen J, Ward JD, Choi S, et al. (1988) Spectral analysis of the EEG in craniocerebral trauma. Can J Neurol Sci 15: 82-86.

74. Nuwer MR, Hovda DA, Schrader LM, Vespa PM (2005) Routine and quantitative EEG in mild traumatic brain injury. Clin Neurophysiol 116: 2001-2025.

75. Kane NM, Moss TH, Curry SH, Butler SR (1998) Quantitative electroencephalographic evaluation of non-fatal and fatal traumatic coma. Electroencephalogr Clin Neurophysiol 106: 244-250. [Crossref]

76. Vespa PM, Boscardin WJ, Hovda DA, McArthur DL, Nuwer MR, et al. (2002) Early and persistent impaired percent alpha variability on continuous electroencephalography monitoring as predictive of poor outcome after traumatic brain injury. $J$ Neurosurg 97 84-92.

77. Hebb MO, McArthur DL, Alger J, Etchepare M, Glenn TC, et al (2007) Impaire percent alpha variability on continuous electroencephalography is associated with thalamic injury and predicts poor long-term outcome after human traumatic brain injury. J Neurotrauma 24: 579-590.

78. Haveman ME, Van Putten MJAM, Hom HW, Eertman-Meyer CJ, Beishuizen A, et al. (2019) Predicting outcome in patients with moderate to severe traumatic brain injury using electroencephalography. Crit Care 23: 401. [Crossref]

79. Guskiewicz KM, Marshall SW, Bailes J, McCrea M, Harding HP, et al. (2007) Recurrent concussion and risk of depression in retired professional football players. Med Sci Sports Exer 39: 903-909.

80. Omalu BI, DeKosky ST, Minster RL, Kamboh MI, Hamilton RL, et al. (2005) Chronic traumatic encephalopathy in a National Football League player. Neurosurgery 57: 128 134

81. Gavett BE, Stern RA, McKee AC (2011) Chronic traumatic encephalopathy: a potential late effect of sport-related concussive and subconcussive head trauma. Clin Sports Med 30: $179-188$.

82. Prichep LS, McCrea M, Barr W, Pwell M, Chabot RJ, et al. (2013) Time course of clinical and electrophysiological recovery after sport-related concussion. $J$ Head Trauma Rehabil 28: 266-273.

83. Ryan LM, Warden DL (2003) Post concussion syndrome. Int Rev Psychiatry 15: 310316

84. Hartlage LC, Durant-Wilson D, Patch PC (2001) Persistent neurobehavioral problems following mild traumatic brain injury. Archives of Clinical Neuropsychology 16: 561570. [Crossref]

85. Bazarian JJ, Wong T, Harris M, Leahey N, Mookerjee S, et al. (1999) Epidemiology and predictors of post-concussive syndrome after minor head injury in an emergency population. Brain Inj 13: 173-189.

86. Niogi SN, Mukherjee P, Ghajar J, Johnson C, Kolster RA, et al. (2008) Extent of microstructural white matter injury in postconcussive syndrome correlates with impaired cognitive reaction time: a $3 \mathrm{~T}$ diffusion tensor imaging study of mild traumatic brain injury. AJNR Am J Neuroradiol 29: 967-973.

87. McCrea M, Prichep L, Powell MR, Chabot R, Barr WB, et al. (2010) Acute effect and recovery after sport-related concussion: a neurocognitive and quantitative brain electrical activity study. J Head Trauma Rehabil 25: 283-292. [Crossref]

88. Barr WB, Prichep LS, Chabot R, Powell MR, McCrea M, et al. (2012) Measuring brain electrical activity to track recovery from sport-related concussion. Brain Inj 26: 58-66.

89. Gay M, Ray W, Johnson B, Teel E, Geromino A, et al. (2015) Feasibility of EEG measures in conjunction with light exercise for return-to-play evaluation after sportsrelated concussion. Dev Neuropsychol 40: 248-253.

90. Munia TTK, Haider A, Schneider C, Rmanick M, Fazel-Rezai R, et al. (2017) A nove EEG based spectral analysis of persistent brain function alteration in athletes with concussion history. Nat Sci Rep 7: 17221. [Crossref]

91. McNerney MW, Hobday T, Cole B, et al. Objective Classification of mTBI Using Machine Learning on a Combination of Frontopolar Electroencephalography Measurements and Self-reported Symptoms. Sports Med Open 25: 14. 
92. Duncan CC, Summers AC, Perla EJ, Coburn KL, Mirsky AF, et al. (2011) Evaluation of traumatic brain injury: brain potentials in diagnosis, function, and prognosis. Int $J$ Psychophysiol 82: 24-40.

93. Huff JS, Naunheim R, Dastidar SG, Bazarian J, Michelson EA, et al. (2017) Referrals for CT scans in mild TBI patients can be aided by the use of a brain electrical activity biomarker. Am J Emerg Med 35: 1777-1779.

94. Echemendia RJ, Meeuwisse W, McCrory P, Davis GA, Putukian M, et al. (2017) The sport concussion assessment tool 5th edition (Scat5): background and rationale. $\mathrm{Br} J$ Sports Med 11: 848-850.

95. Galetta KM, Brandes LE, Maki K, Dziemianowicz MS, Laudano E, et al. (2011) The King-Devick test and sports-related concussion: study of a rapid visual screening tool in a collegiate cohort. J Neurol Sci 15: 34-39.

96. Kang XG, Yang F, Li W, Ma C, Li L, et al. (2015) Predictive value of EEG-awakening for behavioral awakening from coma. Ann Intensive Care 5: 52.

97. De Gennaro L, Ferrara M (2003) Sleep spindles: an overview. Sleep Med Rev 7: 423440.

98. Daltrozzo J, Wioland N, Mutschler V, Kotchoubey B (2007) Predicting coma and other low responsive patients outcome using event-related brain potentials: a meta-analysis. Clin Neurophysiol 118: 606-614.

99. Haneef Z, Levin HS, Frost JD, Mizrahi EM (2013) Electroencephalography and quantitative electroencephalography in mild traumatic brain injury. J Neurotrauma 30 : 653-656. [Crossref]

100. Wijdicks EF, Hijdra A, Young GB, Bassetti CL, Wiebe S, et al. (2006) Practice parameter: prediction of outcome in comatose survivors after cardiopulmonary resuscitation (an evidence-based review): report of the Quality Standards Subcommittee of the American Academy of Neurology. Neurology 67: 203-210.

101. Houlden DA, Taylor AB, Feinstein A, Midha R, Bethune AJ, et al. (2010) Early somatosensory evoked potential grades in comatose traumatic brain injury patients predict cognitive and functional outcome. Crit Care Med 38: 167-174.

102. Robinson LR, Micklesen PJ, Tirschwell DL, Lew H (2003) Predictive value of somatosensory evoked potentials for awakening from coma. Crit Care Med 31: 960967. [Crossref]

103. Ad Hoc Committee (1968) A definition of irreversible coma: Report of the Ad Hoc Committee of the Harvard Medical School to Examine the Definition of Brain Death. JAMA 205: 337-340.

104. Practice parameters for determining brain death in adults (summary statement). The Quality Standards Subcommittee of the American Academy of Neurology. Neurology 45: 1012-1014.

105. Machado C, Kerein J, Ferrer Y, Portela L, de la C García M, et al. (2007) The concept of brain death did not evolve to benefit organ transplants. J Med Ethics 33: 197-200.

106. Wijdicks EF (2002) Brain death worldwide: accepted fact but no global consensus in diagnostic criteria. Neurology 58: 20-25. [Crossref]

107. Wahlster S, Wijdicks EF, Patel PV, Greer DM, Hemphill JC 3rd, et al. (2015) Brain death declaration: practices and perceptions worldwide. Neurology 84: 1870-1879.

108. Black PM, Zervas NT (1984) Declaration of brain death in neurosurgical and neurological practice. Neurosurgery 15: 170-174.

109. Kramer AH (2015) Ancillary testing in brain death. Semin Neurol 35: 125-138.

110. American Clinical Neurophysiology Society. Guideline 3: Minimum technical standards for EEG recording in suspected cerebral death. J Clin Neurophysiol 23: 97-104.

111. Lee SY, Kim WJ, Kim JM, Kim J, Park S, et al. (2017) Electroencephalography for the diagnosis of brain death. Ann Clin Neurophysiol 19: 118-124.

112. Benzinger TL, Brody D, Cardin S (2009) Blast-related brain injury: imaging for clinical and research applications: report of the 2008 st. Louis workshop. $J$ Neurotrauma 26: 2127-2144.

113. Davis CP (2020) CT Scan vs. MRI Differences between Safety, Cost, and Uses. www. medicinenet.com > ct_scan_vs_mri > article. Accessed February 10, 2020.

114. Mittenberg W, Patton C, Canyock EM, Condit DC (2002) Base rates of malingering and symptom exaggeration. J Clin Exp Neuropsychol 24: 1094-1002.

115. Strauss E, Spellacy F, Hunter M, Berry T (1994) Assessing believable deficits on measures of attention and information processing capacity. Arch Clin Neuropsychol 9: 483-490. [Crossref]
116. Osimani A, Alon A, Berger A, Abarbanel JM (1997) Use of the Stroop phenomenon as a diagnostic tool for malingering. J Neurol Neurosurg Psychiatry 62: 617-621.

117. Dockree PM, Robertson IH (2011) Electrophysiological markers of cognitive deficits in traumatic brain injury: a review. Int. J. Psychophysiol 82: 53-60.

118. Patel, Salil H, Azzam PN (2005) Characterization of N200 and P300: selected studies of the event-related potential. Int J Med Sci 2: 147-154.

119. Vagnini VL, Berry DT, Clark JA, Jiang Y (2008) New measures to detect malingered neurocognitive deficit: applying reaction time and event-related potentials. J Clin Exp Neuropsychol 30: 766-776. [Crossref]

120. Neal J, Strothkamp S, Bedingar E (2019) Discriminating Fake From True Brain Injury Using Latency of Left Frontal Neural Responses During Old/New Memory Recognition. Front Neurosci 13: 988.

121. Greve KW, Bianchini KJ, Doane BM (2006) Classification accuracy of the test of memory malingering in traumatic brain injury: results of a known-groups analysis. $J$ Clin Exp Neuropsychol 28: 1176-1190.

122. Green P (2011) Comparison between the Test of Memory Malingering (TOMM) and the Nonverbal Medical Symptom Validity Test (NV-MSVT) in adults with disability claims. Appl Neuropsychol 18: 18-26.

123. Rees LM, Tombaugh TN, Boulay L (2001) Depression and the Test of Memory Malingering. Arch Clin Neuropsychol 16: 501-506. [Crossref]

124. Hoover S, Zottoli T, Grose-Fifer J (2014) ERP correlates of malingered executive disfunction. Int. J. Psychophysiol 91: 139-146.

125. Barth J, Macciocchi S, Giordani B (1983) Neuropsychological sequelae of minor head injury. Neurosurgery 13: 520-537

126. Kwentus JA, Hart RP, Peck ET (1985) Psychiatric complications of closed head trauma. Psychosomatics 26: 8-15

127. Rimel R, Hiodani B, Barth J (1981) Disability caused by minor head injury. Neurosurgery 9: 221-223

128. Koufen H, Dichgans J (1978) Frequency and course of posttraumatic EEGabnormalities and their correlations with clinical symptoms: a systematic follow up study in 344 adults. Fortschr Neurol Psychiat Grenzgeb 46: 165-177.

129. Dow RS, Ulett G, Raaf J (1944) Electroencephalographic studies immediately following head injury. Am J Psychiatry 101: 174-83.

130. Geets W. Louette N (1985) Early EEG in 300 cerebral concussions. (Fre) Rev. Electroencephalogr Neurophysiol Clin 14: 333-338. [Crossref]

131. Ianof JN, Anghinah R (2017) Traumatic brain injury: An EEG point of view. Dement Neuropsychol 11: 3-5.

132. Russel WR, Nathan PW (1946) Traumatic amnesia. Brain 69: 183-187

133. Levin HS, Benton AL, Grossman RG (1982) Neurobehavioral Consequences of Closed Head Injury. New York, Oxford University Press, 1982.

134. Lewine JD, Davis JT, Bigler ED, Thoma R, Hill D, et al. (2007) Objective documentation of traumatic brain injury subsequent to mild head trauma multimodal brain imaging with MEG, SPECT, and MRI. J. Head Trauma Rehabil 22: 141-155.

135. Rapp PE, Keyser DO, Albano A (2015) Traumatic brain injury detection using electrophysiological methods. Front Hum Neurosci 9:11. [Crossref]

136. Amyot F, Arciniegas DB, Brazaitis MP (2015) A Review of the Effectiveness of Neuroimaging Modalities for the Detection of Traumatic Brain Injury. J Neurotrauma 32: $1693-1721$.

137. ES Papathanasiou, T Cronin, B Seemungal, J Sandhu (2018) Electrophysiological testing in concussion: A guide to clinical applications. Journal of Concussion 3: 1-11.

138. Silva PE, Maldaner V, Vieira L, de Carvalho KL, Gomes H, et al. (2018) Neuromuscular electrophysiological disorders and muscle atrophy in mechanicallyventilated traumatic brain injury patients: New insights from a prospective observational study. J Crit Care 44: 87-94.

139. Di Virgilio TG, Hunter A, Wilson L (2016) Evidence for Acute Electrophysiological and Cognitive Changes Following Routine Soccer Heading. EBioMedicine 13: 6671. [Crossref]

140. Gosselin N, Bottari C, Chen JK, Huntgeburth SC, De Beaumont L, et al. (2012) Evaluating the cognitive consequences of mild traumatic brain injury and concussion by using electrophysiology. Neurosurg Focus 33: E7: 1-7. 
141. Beres AM (2017) Time is of the Essence: A Review of Electroencephalography (EEG) and Event-Related Brain Potentials (ERPs) in Language Research. App Psychophysiol Biofeedback 42: 247-255.

142. Boshra R, Ruiter KI, DeMatteo C, Reilly JP, Connolly JF, et al. (2019) Neurophysiological Correlates of Concussion: Deep Learning for Clinical Assessment. Sci Rep 9: 17341.

143. Nandrajog P, Idris Z, Azlen WN, Liyana A, Abdullah JM, et al. (2017) The use of event-related potential (P300) and neuropsychological testing to evaluate cognitive impairment in mild traumatic brain injury patients. Asian J Neurosurg 12: 447-453.

144. T Seifert, M Cecchi (2018) Use of Event Related Potential Markers in Patients with Traumatic Brain Injury. Neurology 90: P6.305.

145. Fratantoni JM, DeLaRosa BL, Didehbani N, Hart J Jr, Kraut MA, et al. (2017) Electrophysiological Correlates of Word Retrieval in Traumatic Brain Injury. $J$ Neurotrauma 34: 1017-1021.

146. Sun H, Luo C, Chen X, Tao L (2017) Assessment of cognitive dysfunction in traumatic brain injury patients: a review. Forensic Sci Res 2: 174-179.

147. "Cognition - definition of cognition in English from the Oxford dictionary." Available from: https://en.oxforddictionaries.com/definition/cognition. Accessed February 10, 2020

148. Wolf JA, Koch PF (2016) Disruption of network synchrony and cognitive dysfunction after traumatic brain injury. Front Syst Neurosci 43:1-14. [Crossref]

149. Witgen BM, Lifshitz J, Smith ML (2005) Regional hippocampal alteration associated with cognitive deficit following experimental brain injury: a systems, network and cellular evaluation. Neuroscience 133: 1-15.

150. Larson MJ, Kaufman DA, Kellison IL (2009) Double jeopardy! The additive consequences of negative affect on performance-monitoring decrements following traumatic brain injury. Neuropsychology 23: 433-444.

151. Perlstein WM, Larson MJ, Dotson VM (2006) Temporal dissociation of components of cognitive control dysfunction in severe TBI: ERPs and the cued-Stroop task. Neuropsychologia 44: 260-274.

152. Larson MJ, Farrer TJ, Clayson PE (2011) Cognitive control in mild traumatic brain injury: conflict monitoring and conflict adaptation. Int J Psychophysiol 82: 69-78.

153. Chen AJ, D'Esposito M (2010) Traumatic brain injury: from bench to bedside [corrected] to society. Neuron 66 : 11-14.

154. Lew HL, Poole JH, Chiang JY (2005) Event-related potential in facial affect recognition: potential clinical utility in patients with traumatic brain injury. $J$ Rehabil Res Dev 42: 29-34.

155. Green L, Godfrey C, Soo C (2013) A preliminary investigation into psychosocia outcome and quality-of-life in adolescents following childhood traumatic brain injury. Brain Inj 27: 872-877. [Crossref]

156. Bogart E, Togher L, Power E (2012) Casual conversations between individuals with traumatic brain injury and their friends. Brain Inj 26: 221-233.

157. Lachapelle J, Bolduc-Teasdale J, Ptito A (2008) Deficits in complex visua information processing after mild TBI: electrophysiological markers and vocational outcome prognosis. Brain Inj 22: 265-274

158. Saxton ME, Younan SS, Lah S (2013) Social behaviour following severe traumatic brain injury: contribution of emotion perception deficits. Neurorehabilitation 33 263-271. [Crossref]

159. Sutherland J, Middleton J, Ornstein TJ (2016) Assessing accident phobia in mild traumatic brain injury: the accident fear questionnaire. Rehabil Psychol 61: 317-327.

160. Benedictus MR, Spikman JM, van der Naalt J (2010) Cognitive and behavioral impairment in traumatic brain injury related to outcome and return to work. Arch Phys Med Rehabil 91: 1436-1441.

161. McFadden KL, Healy KM, Dettmann ML (2011) Acupressure as a nonpharmacological intervention for traumatic brain injury (TBI). $J$ Neurotrauma 28 : 21-34

162. Pachalska M, Lukowicz M, Kropotov JD (2011) Evaluation of differentiated neurotherapy programs for a patient after severe TBI and long term coma using event-related potentials. Med Sci Monit 17: S120-S128

163. Yu Z, Morrison BR (2010) Experimental mild traumatic brain injury induces functional alteration of the developing hippocampus. J Neurophysiol 103: 499-510.

164. Larson MJ, Clayson PE, Farrer TJ (2012) Performance monitoring and cognitive control in individuals with mild traumatic brain injury. J Int Neuropsychol Soc 18: 323-333.
165. Amantini A, Grippo A, Fossi S (2005) Prediction of 'awakening' and outcome in prolonged acute coma from severe traumatic brain injury: evidence for validity of short latency SEPs. Clin Neurophysiol 116: 229-235.

166. Larson MJ, Kaufman DA, Schmalfuss IM (2007) Performance monitoring, error processing, and evaluative control following severe TBI. J Int Neuropsychol Soc 13 961-971. [Crossref]

167. Larson MJ, Kaufman DA, Perlstein WM (2009) Conflict adaptation and cognitive control adjustments following traumatic brain injury. J Int Neuropsychol Soc 15 : 927-937.

168. Sozda CN, Larson MJ, Kaufman DA (2011) Error-related processing following severe traumatic brain injury: an event-related functional magnetic resonance imaging (fMRI) study. Int J Psychophysiol 82: 97-106.

169. Kodama T, Morita K, Doi R (2010) Neurophysiological analyses in different color environments of cognitive function in patients with traumatic brain injury. $J$ Neurotrauma 27: 1577-1584.

170. Lew HL, Thomander D, Gray M (2007) The effects of increasing stimulus complexity in event-related potentials and reaction time testing: clinical application in evaluating patients with traumatic brain injury. J Clin Neurophysiol 24: 398-404.

171. Doi R, Morita K, Shigemori M (2007) Characteristics of cognitive function in patients after traumatic brain injury assessed by visual and auditory event-related potentials. Am J Phys Med Rehabil 86: 641-649.

172. Reza MF, Ikoma K, Ito T (2007) N200 latency and P300 amplitude in depressed mood post-traumatic brain injury patients. Neuropsychol Rehabil 17: 723-734.

173. Cui Y, Liu F, Zhang XY (2009) Auditory P300 in the patients with traumatic brain injury. Fa Yi Xue Za Zhi 25: 19-23. [Crossref]

174. Sarno S, Erasmus LP, Frey M (2006) Electrophysiological correlates of active and passive attentional states after severe traumatic brain injury. Funct Neurol 21: 21-29.

175. Zarza-Lucianez D, Arce-Arce S, Bhathal H (2007) Mismatch negativity and conscience level in severe traumatic brain injury. Rev Neurol 44: 465-468.

176. Morlet D, Fischer C (2014) MMN and novelty P3 in coma and other altered states of consciousness: a review. Brain Topogr 27: 467-479.

177. Fleck-Prediger CM, Ghosh Hajra S, Liu CC (2018) Point-of-care brain injury evaluation of conscious awareness: wide scale deployment of portable HCS EEG evaluation. Neurosci Conscious.

178. Verma A, Anand V, Verma NP (2007) Sleep disorders in chronic traumatic brain injury. J Clin Sleep Med 3: 357-362.

179. Urakami Y, Ioannides A, Kostopoulos G (2020) Sleep Spindles - As a Biomarker of Brain Function and Plasticity, Advances in Clinical Neurophysiology, Ihsan M. Ajeena, IntechOpen.

180. Urakami Y (2008) Relationships Between Sleep Spindles and Activities of Cerebral Cortex as Determined by Simultaneous EEG and MEG Recording. $J$ Clin Neurophysiol 25: 13-24.

181. Urakami Y (2012) Relationships between sleep spindles and clinical outcome in patients with traumatic brain injury: a simultaneous EEG and MEG study. Clin EEG Neurosci 43: 39-47.

182. Thatcher RW, Camacho M, Salazar A, Linden C (1997) Quantitative MRI of the gray-white matter distribution in traumatic brain injury. J Neurotrauma 14: 1-14 [Crossref]

183. Pevzner A, Izadi A, Lee DJ, Shahlaie K, Gurkoff GG (2016) Making Waves in the Brain: What Are Oscillations, and Why Modulating Them Makes Sense for Brain Injury. Front Syst. Neurosci 10: 30.

184. Reijneveld JC, Ponten SC, Berendse HW, Stam CJ (2007) The application of graph theoretical analysis to complex networks in the brain. Clin Neurophysiol 118: 2317 2331.

185. Varela F, Lachaux JP, Rodriguez E, Martinerie J (2001) The brainweb: Phase synchronization and large-scale integration. Nat Rev Neurosci 2: 229-239.

186. Silberstein RB, Song J, Nunez PL, Park W (2004) Dynamic sculpting of brain functional connectivity is correlated with performance. Brain Topogr 16: 249-254.

187. Achard S, Salvador R, Whitcher B, Suckling J, Bullmore E, et al. (2006) A resilient, low-frequency, small-world human brain functional network with highly connected association cortical hubs. J Neurosci 26: 63-72. [Crossref]

188. Sporns O, Zwi JD (2004) The small world of the cerebral cortex. Neuroinformatic. 2: $145-162$ 
189. Sporns O, Chialvo DR, Kaiser M, Hilgetag CC (2004) Organization, development and function of complex brain networks. Trends Cogn Sci 8: 418-425.

190. Sporns O (2011) Networks of the Brain. 2011. Cambridge, MA: MIT Press

191. Raichle ME, Snyder AZ (2007) A default mode of brain function: a brief history of an evolving idea. Neuroimage 37: 1083-1090

192. Raichle ME (2011) The restless brain. Brain Connect 1: 3-12

193. Raichle ME (2015) The restless brain: how intrinsic activity organizes brain function. Philos Trans R Soc Lond B Biol Sci 370: 20140172. [Crossref]

194. Petersen SE, Posner MI (2012) The attention system of the human brain: 20 years after. Annu Rev Neurosci 35: 73-89.

195. Etkin A, Prater K, Hoeft F, Menon V (2010) Failure of Anterior Cingulate Activation and Connectivity with the Amygdala During Implicit Regulation of Emotional Processing in Generalized Anxiety Disorder. Am J Psychiatry 167: 545-554.

196. Ernst M (2010) Conflict adaptation in generalized anxiety disorder: small paradigm twist, large scientific leap. Am J Psychiatry 167: 489-492.

197. Raichle ME, MacLeod AM, Snyder AZ, Powers WJ, Gusnard DA, et al. (2001) A default mode of brain function. Proc Natl Acad Sci U S A 98: 676-682.

198. Mesulam MM, Rogalski EJ, Wieneke C (2014) Primary progressive aphasia and the evolving neurology of the language network. Nat Rev Neurol 10: 554-569.

199. Mesulam MM (2001) Primary progressive aphasia. Ann. Neurol 49: 425-432.

200. D'Ardenne K, Eshel N, Luka J, Lenartowicz A, Nystrom LE, et al. (2012) Role of prefrontal cortex and the midbrain dopamine system in working memory updating. Proc Natl Acad Sci U S A 109: 19900-19909.

201. Ulrich-Lai YM, Herman JP (2009) Neural regulation of endocrine and autonomic stress responses. Nat Rev Neurosci 10: 397-409.

202. Jacobs EG, Holsen LM, Lancaster K (2015) 17ß-estradiol differentially regulates stress circuitry activity in healthy and depressed women. Neuropsychopharmacology 40: 566-576.

203. Stern J, Jeanmonod D, Sarnthein J (2006) Persistent EEG overactivation in the cortical pain matrix of neurogenic pain patients. Neuroimage 31: 721-731.

204. Sridharan D, Levitin DJ, Menon VA (2019) critical role for the right fronto-insular cortex in switching between central-executive and default-mode networks. Proc Natl. Acad. Sci. U.S.A 105: 12569-12574

205. Stam CJ (2004) Functional connectivity patterns of human magnetoencephalographic recordings: a "small-world" network? Neurosci Lett 355: 25-28.

206. Watts DJ, Strogatz SH (1998) Collective dynamics of 'small-world' networks. Nature 393: $440-442$.

207. Stam C (2007) Small-World Networks and Functional Connectivity in Alzheimer's Disease. Cereb Cortex 17: 92-99. [Crossref]

208. Jacobs EG, Holsen LM, Lancaster K (2015) 17ß-estradiol differentially regulates stress circuitry activity in healthy and depressed women. Neuropsychopharmacology 40: 566-576.

209. Thatcher RW (2011) Neuropsychiatry and quantitative electroencephalography in the 21st century. Neuropsychiatry 1: 495-514

210. Thatcher RW, North DM, Biver CJ (2012) Diffusion spectral imaging modules correlate with EEG LORETA neuroimaging modules. Hum Brain Mapp 33: 10621075 .

211. Thatcher RW, North DM, Biver CJ (2014) LORETA EEG phase reset of the defaul mode network. Front Hum Neurosci 8: 529.

212. Fuster JM, Alexander GE (1971) Neuron activity related to short-term memory Science 173: 652-654. [Crossref]

213. Chafee MV, Goldman-Rakic PS (1998) Matching patterns of activity in primate prefrontal area $8 \mathrm{a}$ and parietal area 7ip neurons during a spatial working memory task. J Neurophysiol 79: 2919-2940.

214. Batuev AS, Pirogov AA, Orlov AA. Unit activity of the prefrontal cortex during delayed alternation performance in monkey. Acta Physiol Acad Sci Hung 53: $345-$ 353

215. Funahashi S (2006) Prefrontal cortex and working memory processes. Neuroscience 139: $251-261$
216. Lycke C, Specht K, Ersland L, Hugdahl K (2008) An fMRI study of phonological and spatial working memory using identical stimuli. Scand J Psychol 49: 393-401.

217. Olthoff A, Baudewig J, Kruse E, Dechent P (2008) Cortical sensorimotor control in vocalization: A functional magnetic resonance imaging study. Laryngoscope 118: 2091-2096.

218. Slobounov SM, Simon R, Tutwiler R, Ray WJ (2000) EEG correlates of wris kinematics as revealed by averaging techniques and Morlet wavelet transforms. Motor Control 4: 350-372. [Crossref]

219. Slobounov SM, Ray WJ (1998) Movement-related potentials with reference to isometric force output in discrete and repetitive tasks. Exp Brain Res 123: 461-473.

220. Greicius MD, Krasnow B, Reiss AL, Menon V (2003) Functional connectivity in the resting brain: A network analysis of the default mode hypothesis. Proc Natl Acad Sci USA 100: 253-258.

221. Steriade M, Gloor P, Llinas RR, da Silva FHL (1990) Report of IFCN Committee on Basic Mechanisms: Basic mechanisms of Cerebral Rhythmic Activities, Electroencephalography and Clinical Neurophysiology 76: 481-508

222. Nuwer M, Hovda DA, Schrader LM, Vespa PM (2005) Routine and Quantitative EEG in Mild Traumatic Brain Injury; Clinical Neurophysiology 116: 2001-2025

223. Thatcher RW, Camacho M, Salazar A, Linden C, (1997) Quantitative MRI of GrayWhite Matter Distribution in Traumatic Brain Injury. Journal of Neurotrauma 14: $1-14$

224. Thatcher RW (1999) QEEG and Traumatic Brain Injury: Rebuttal of the American Academy of Neurology 1997. A Report by the EEG and Clinical Neuroscience Society, Clinical Electroencephalography 30: 94-98.

225. Li S (2015) Clinical utility of brain stimulation modalities following traumatic brain injury: current evidence. Neuropsychiatr Dis Treat 11: 1573-1586.

226. Gennarelli TA (1982) Diffuse axonal injury and traumatic coma in the primate. Ann Neurol 12: 564-574.

227. Adams JH (1989) Diffuse axonal injury in head injury: definition, diagnosis and grading. Histopathology 15: 49-59. [Crossref]

228. Gentleman SM (1995) Axonal injury: a universal consequence of fatal closed head injury? Acta Neuropathol 89: 537-543.

229. Bergquist $T$ (2009) The effect of internet-based cognitive rehabilitation in persons with memory impairments after severe traumatic brain injury. Brain Inj 23: 790-799.

230. Lundqvist A (2010) Computerized training of working memory in a group of patients suffering from acquired brain injury. Brain Inj 24: 1173-1183

231. Fitzgerald PB, Hoy KE, Maller JJ (2011) Transcranial magnetic stimulation for depression after a traumatic brain injury: a case study. J ECT 27: 38-40.

232. Cosentino G (2010) A case of post-traumatic complex auditory hallucinosis treated with rTMS. Neurocase 16: 267-272. [Crossref]

233. Louise-Bender Pape T (2009) Repetitive transcranial magnetic stimulation-associated neurobehavioral gains during coma recovery. Brain Stimul 2: 22-35.

234. Lefaucheur JP (2014) Evidence-based guidelines on the therapeutic use of repetitive transcranial magnetic stimulation (rTMS). Clin Neurophysiol 125: 2150-2206

235. Wigton NL (2013) Clinical Perspectives of 19-Channel Z-Score Neurofeedback: Benefits and Limitations. Journal of Neurotherapy 17: 259-264.

236. Koberda JL (2013) Pain Management Using 19-Electrode Z-Score LORETA Neurofeedback. Journal of Neurotherapy 17: 179-190.

237. Thatcher RW (2013) Latest Developments in Live Z-Score Training: Symptom Check List, Phase Reset, and Loreta Z-Score Biofeedback, Journal of Neurotherapy 17: 69-87.

238. Ulam F (2015) Cumulative effects of transcranial direct current stimulation on EEG oscillations and attention/working memory during subacute neurorehabilitation of traumatic brain injury. Clin Neurophysiol 126: 486-496. [Crossref]

239. Neville IS, Zaninotto AL, Hayashi CY (2019) Repetitive TMS does not improve cognition in patients with TBI: A randomized double-blind trial. Neurology 93: e190-e199.

240. Case Study Testimonials: What Our Clinicians Say about Using NeuroGuide ${ }^{\mathrm{TM}}$ and Neurofeedback. Z score biofeedback has transformed the field of neurofeedback https://appliedneuroscience.com/case-study-testimonials/. Accessed February 10, 2020. 
Miranda P (2020) Electroencephalography (EEG)-based detection, management, recovery and brain retraining tracking of Traumatic Brain Injury (TBI) when “Only Time Can Tell'

241. Dockree PM (2011) Electrophysiological markers of cognitive deficits in traumatic brain injury: a review. Int J Psychophysiol 82: 53-60. [Crossref]
242. Gomes J (2017) Event-Related Potentials as Biomarkers of Mild Traumatic Brain Injury. Act Nerv 59: 87-90.

Copyright: $\odot 2020$ Miranda P. This is an open-access article distributed under the terms of the Creative Commons Attribution License, which permits unrestricted use, distribution, and reproduction in any medium, provided the original author and source are credited. 